\title{
Stereoselective Organocatalytic Addition of Nucleophiles to Isoquinolinium and 3,4-dihydroisoquinolinium Ions: A Simple Approach for the Synthesis of Isoquinoline Alkaloids
}

\author{
Andrea Gualandi • Luca Mengozzi • \\ Elisabetta Manoni • Pier Giorgio Cozzi
}

Received: 25 September 2014/ Accepted: 1 October 2014/Published online: 31 October 2014

(C) Springer Science+Business Media New York 2014

\begin{abstract}
The frequent occurrence of chiral 1-substituted1,2,3,4-tetrahydroisoquinoline ring systems in a large number of alkaloids, possessing a broad spectrum of biological and pharmaceutical properties, has prompted out a considerable interest in their synthesis. Economical and valuable stereoselective processes based on organocatalytic transformations represent a new avenue for approaching isoquinoline alkaloids with efficiency and creativity.
\end{abstract}

Keywords Asymmetric catalysis - Homogeneous catalysis - Green chemistry

\section{Introduction}

Tetrahydroisoquinoline derivatives are structural motifs often occurring in natural products such as isoquinoline alkaloids, the largest group of alkaloids (Fig. 1) [1]. The tetrahydroisoquinoline skeleton is a basic building block of various types of alkaloids including benzylisoquinolines (among them papaverine, hygenamine, laudanosine and micovarium), protopines, benzo[c]phenanthridines, protoberberines, naphtylisoquinolines, bisbenzylisoquinolines (berbamine, dauricine, fangchinoline, pavines and isopavines), phtalide isoquinoline (bicuculline), emetine group, aporphinoid alkaloids, morphine, colchicines, and many

\footnotetext{
A. Gualandi $(\bowtie) \cdot$ L. Mengozzi · E. Manoni · P. G. Cozzi $(\bowtie)$ Dipartimento di Chimica "G. Ciamician", ALMA MATER STUDIORUM, University of Bologna, Via Selmi 2, 40126 Bologna, Italy

e-mail: andrea.gualandi10@unibo.it

P. G. Cozzi

e-mail: Piergiorgio.cozzi@unibo.it
}

others. These natural products are found in a great variety of plants and vegetables and they often exhibit a range of pharmacologically and biological activities such as antitumor, antibiotic, antiviral anti-inflammatory, anticoagulation, and bronchodilation [2]. Therefore, the frequent occurrence of chiral 1-substituted-1,2,3,4-tetrahydroisoquinoline ring systems in a large number of alkaloids possessing a broad spectrum of biological and pharmaceutical properties, has led to significant increasing interest in their synthesis [3].

To date, most of the traditional synthetic approaches are based on procedures employing chiral building blocks, chiral auxiliaries, or chiral reagents [4]. In order to address issues related to economic and ecologically valuable processes, in recent years considerable effort has been directed towards the development of catalytic stereoselective transformations to obtain enantioenriched 1-substitutedtetrahydroisoquinoline frameworks with a high level of selectivity. As the biological activity of such alkaloids is often displayed by a specific stereoisomer [5], many efforts have been directed to asymmetrically functionalize isoquinolines. Many methodologies focus on the introduction of a substituent at the $\mathrm{C} 1$ position [6], as this stereocenter is present in most of the natural products in this compound class [7]. This chemistry was first explored by Reissert [8] using chloroformate or benzoyl chloride to activate either isoquinolines or quinolines which react via the corresponding acyl iminium ions. The enantioselective catalytic version of the Reissert reaction was introduced by Shibasaki a number of years later [9], indicating the difficulties encountered during the reaction development. Following this, a number of enantioselective metal catalysed methodologies were described [10] for these molecules, however with only moderate success. Another important approach to consider for these compounds is the efficient 
Fig. 1 Some pharmaceutically relevant 1 -substituted tetrahydroquinolines<smiles>COc1ccc2cc3[n+](cc2c1OC)CCc1cc2c(cc1-3)OCO2</smiles>

berberine, 1a<smiles>COc1cc2c(cc1OC)[C@H](CO)NCC2</smiles>

(-)-calycotomine A, 1d<smiles>COc1cc2c(cc1OC)[C@]1(C)c3ccc(OC)c(OC)c3CN1CC2</smiles>

(+)-corydaline, $\mathbf{1 b}$<smiles>COc1cc2c(cc1O)[C@H](CCCCCOC(C)(C)C)NCC2</smiles>

(+)-colchietine, $1 \mathrm{e}$<smiles>COc1cc2c(cc1OC)[C@H]1CCCN1CC2</smiles><smiles>CC[C@H]1CN2CCc3cc(OC)c(OC)cc3[C@H]2CC1C[C@@H]1NCCc2cc(OC)c(OC)cc21</smiles><smiles>CN1CC[C@]23c4c5ccc(O)c4O[C@H]2[C@H](O)C=C[C@H]3C[C@@H]51</smiles>

crispine $\mathrm{A}, \mathbf{1 g}$

asymmetric hydrogenation [11] and asymmetric transfer hydrogenation [12] of 1-substituted-3,4-dihydroisoquinolines (DHIQ). These methodologies are able to conjugate operational efficiency with atom economy. However, despite the advances in asymmetric hydrogenations and the maturity of the technique, only relatively few catalytic systems operating with high selectivity have been reported in the literature, and the asymmetric reduction of 1-arylsubstituted-3,4-DHIQs has only been described in few cases and it is still considered a challenge in the field of asymmetric hydrogenation [13]. The major problem associated with the cited methodologies is the use of metals. Although the impact of metal-based catalysts on chemical synthesis cannot be understated, expensive methodologies and toxicity are often associated with the use of metals. The advent of organocatalysis in 2000 [14, 15] introduced new concepts in catalysis, making possible to design new processes with different experimental procedures, allowing the development of complementary methods able to reduce costs, energy, and chemical waste. The benefits associated with organocatalysis rely on the use of organic molecules, moisture and oxygen stable, and prepared from available precursors, often aminoacids, alkaloids, or from other natural sources already available as single enantiomers. These organic catalysts, or as are now called "organocatalysts" are able to play a specific role in the reaction. It is now well established that organocatalysts are able to promote a reaction and transmit the stereochemical information through generic modes of catalyst activation, induction and reactivity. In a such generic activation mode the reactive specie, that can participate in many reaction types, is formed by the interaction of the organocatalyst with a functional group (e.g.: ketone, aldehyde, imine, nitro, ester or an unsaturated Michael acceptor) present in the reaction mixture, in a highly organized and predictable manner. In a pioneering and inspiring paper [16] activation modes in organocatalysis have been classified, helping many new players to enter into this field and accelerating the exponential growth of the subject. The paradigm of generic activation modes allows straightforwardly the design on many new enantioselective reactions. Indeed, more than 100 organocatalytic reactions were quickly discovered from the use of only five or six activation modes. The small number of activation modes in the field of organocatalysis cannot force readers to think that all mechanisms are established and that these general principles are fully understood [17]. On the contrary more detailed mechanistic investigations and analysis will be useful for solving open problems related to some drawbacks in organocatalysis, such as the low turnover numbers that might limit the potential uses of organocatalysis for industrial applications. In our overview we will summarize the recent methodologies that are using stereoselective organocatalysis in the addition of nucleophiles to 3,4-dihydroisoquinolinium and isoquinolinium ions. Basically, an activation mode of organocatalysis is creating nucleophiles in the presence of activated electrophiles. In the end, the organocatalytic reaction is determined by the interaction of nucleophiles with electrophiles. The reaction rate can be rationalized and even predicted using the concepts developed by Mayr with his scale of reactivity [18]. The Mayr's table can be therefore quite useful to understand and rationalize the behaviour of organocatalysis, particularly when additives and tailored reaction conditions are employed. We will try 

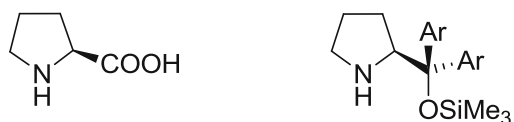

Proline: List, Barbas; I Ar $=$ Ph: Hayashi catalyst; II

$\mathrm{Ar}=3,5-\left(\mathrm{CF}_{3}\right)_{2}-\mathrm{C}_{6} \mathrm{H}_{3}$ : Jørgensen catalyst; III
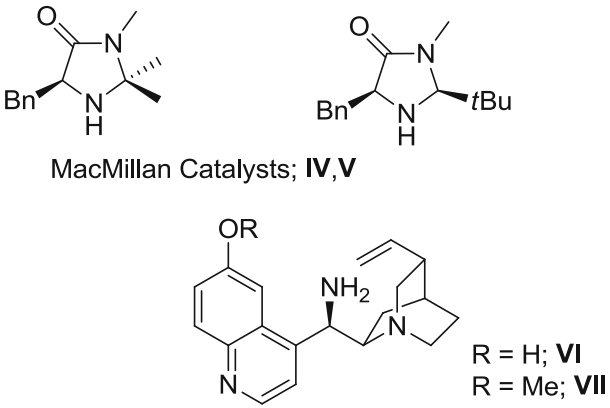

Cinchona based primary amines

Fig. 2 Structures of the principal organocatalysts

to underline simple and useful points for this review, in a brief introduction on organocatalytic activation modes and their connection to the Mayr'scale. Few organocatalytic activation modes (enamine catalysis, hydrogen bond catalysis, and carbene catalysis) will be generally introduced and described in relation to addition to iminium and isoquinolinium ions; through this reaction useful intermediates were prepared for the synthesis of isoquinoline alkaloids or related compounds, that will be the main topic of this review.

\section{Organocatalytic Activation Modes and Their Role in the Reaction with Iminium and Isoquinolinium Ions}

Organocatalytic procedures and studies have grown exponentially in the last decade, and organocatalytic modes of activation are also currently employed in the synthesis of complex natural products [19] and in drug development [20]. Most of the stereoselective organocatalytic reactions are based on the basic activation modes of enamino- [21] and iminium catalysis [22], as displayed by selected secondary amines bearing a pyrrolidine core [23]. Also primary amines derived from Cinchona alkaloids were used in many reactions due to their properties to control nucleophilic addition [24]. To these secondary and primary amines the nickname "working-horses" [25] of enantioselective organocatalysis was assigned. Proline, proline derivatives, Cinchona based amine, and other five-member heterocycles (structures I-VII, Fig. 2) have found an extensive use in organocatalysis field. Three catalysts are worth to mention, in particular the most commonly used diaryl-pyrrolidine derivatives, the Hayashi and Jørgensen organocatalysts II-III [26], the MacMillan type catalysts
IV and $\mathbf{V}$ and the Cinchona primary amines VI-VII. These catalysts are normally employed when enamine or iminium activation modes are designed for the desired transformation.

\subsection{Enamine Activation Mode: Enamine-Activated Reactions}

When proline and proline derived catalysts are employed, the catalytic cycle depicted in Fig. 3 represents the generally accepted mechanism [27] for enamine-activated reactions. A key-step, not necessarily the rate-determining step, is the attack of an electrophile $\mathbf{4}$ to the enamine $\mathbf{3}$. For this organocatalytic reaction the most comprehensive nucleophilicity and electrophilicity scales, presently available, can be also applied. The scale is based on Eq. 1, where electrophiles are characterized by one solventindependent parameter $\mathrm{E}$, and nucleophiles are characterized by two solvent-dependent parameters, the nucleophilicity parameter $\mathrm{N}$ and the sensitivity parameter $\mathrm{s}_{\mathrm{N}}$ [28].

$\log \mathrm{k}\left(20^{\circ} \mathrm{C}\right)=\mathrm{s}_{N}(\mathrm{E}+\mathrm{N})$

The scale was constructed by reference electrophiles (benzhydrylium ions and structurally related quinone methides) and covers a reactivity range of 32 orders of magnitude. With these different reactive electrophiles Mayr and co-workers have been able to compare nucleophiles of widely differing structure and reactivity [29]. The reactivity scales could be employed for designing syntheses by applying the Mayr's rule of thumb [30] that states that "an electrophile can be expected to react with nucleophiles at room temperature when $\mathrm{E}+\mathrm{N}>-5$ ". The Jørgensen-Hayashi catalysts II-III have previously been employed to catalyse reactions of aldehydes and ketones with weak electrophiles, (for example $\beta$-nitrostyrene, $\mathrm{E}=-13.9$ ), because they afford more nucleophilic enamines compared to Macmillan catalysts IV-V. Indeed, these less basic imidazolidinones, which yield the less nucleophilic intermediate enamines, are suitable catalysts for reactions with stronger electrophiles, such as stabilized carbenium ions [31].

In most of the reactions examined in this review, nucleophilic enamines are poured to react with electrophilic iminium ions and isoquinolinium ions. Although the isoquinolinium electrophilic parameter has not been determined yet, Klussmann [32, 33] has recently estimated the electrophilicity parameter $\mathrm{E}$ of a $\mathrm{N}$-phenyl-3,4-dihydroisoquinolinium 6, a key intermediate in many organocatalytic nucleophilic additions described in literature (Fig. 4). The value estimated by Klussmann between -8 and -9 , is in line with electrophilicity parameters determined by Mayr and co-workers for comparable iminium ions, which lie between -5 and -10 [34]. 
Fig. 3 Catalytic cycle in enamine catalysis and nucleophilicity scale of chiral enamines obtained with the organocatalyst II, IV and V

\section{Nucleophilicity $N$}
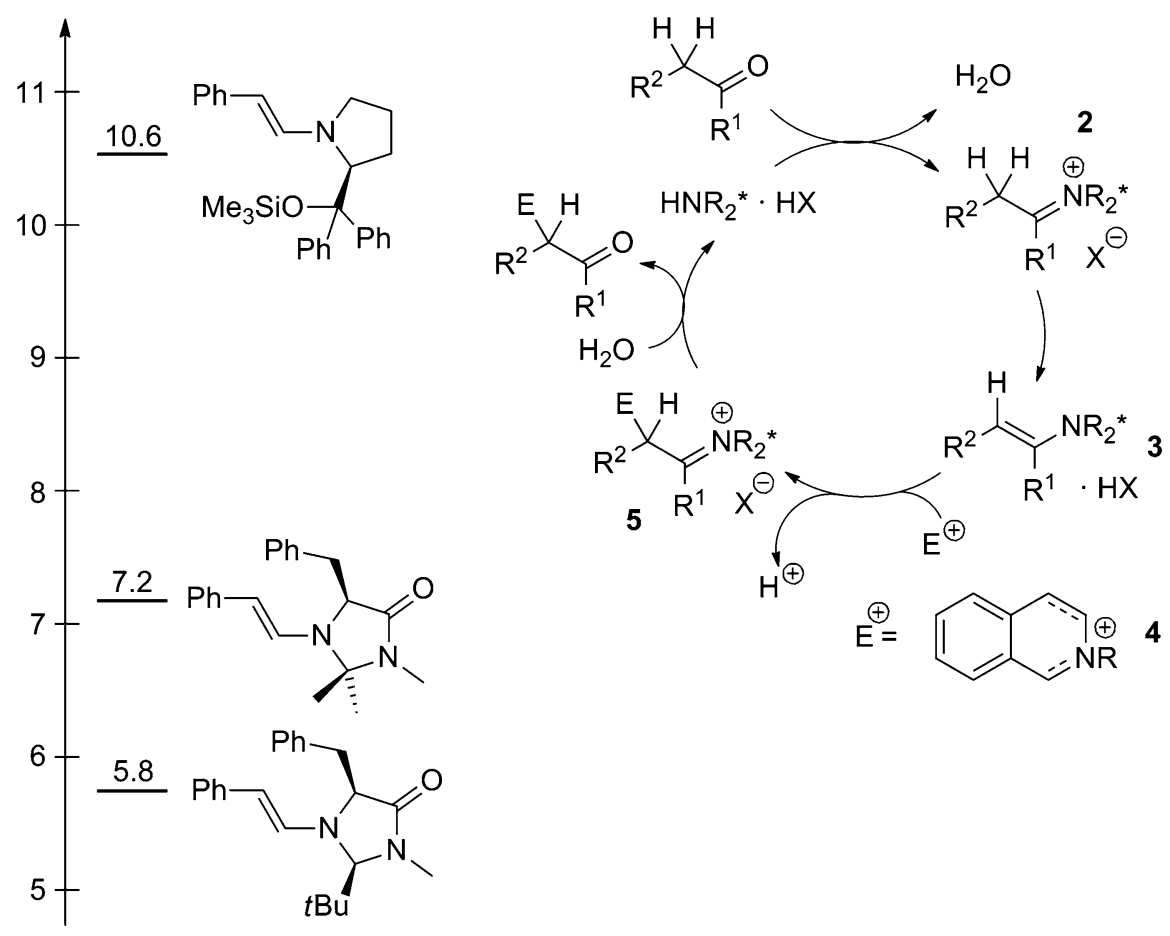

Charged chiral catalyst<smiles>ClC(Cl)(Cl)c1ccccc1</smiles>

$\mathrm{RX}$

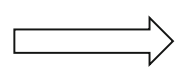

$\stackrel{\oplus}{\mathrm{R}}$

Chiral catalyst

$\Theta$

$\mathrm{RX}$
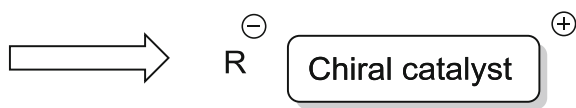

Neutral chiral catalyst

$\mathrm{RX}$
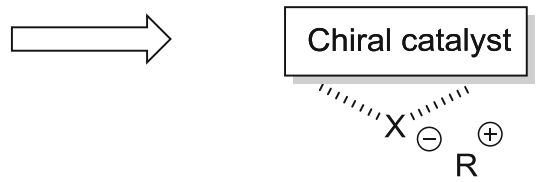
low electrophilicity of the iminium derivative, it is simple to predict that only the most nucleophilic enamine derived from Hayashi-Jørgensen catalyst will be able to react with intermediates of type $\mathbf{6}$.

\subsection{Hydrogen Bond Activation Mode: the Asymmetric Counteranion-Directed Catalysis (ACDC) Ion Pairing}

Organocatalyst can be designed for inducing an ion pair formation. The non-covalent binding of a chiral neutral catalyst to the intermediate ion pair (Fig. 5) can be used to transmit chiral information. Both the anion or the cation can be surrounded by the chiral ligand, and neutral or charged catalysts could be employed.
Fig. 4 Intermediates characterized by Klussmann in the oxidative From the electrophilicity value determined by Klussmann it is possible to rationalize many reactions summa-
rized in this review. It is worth mentioning that due to the
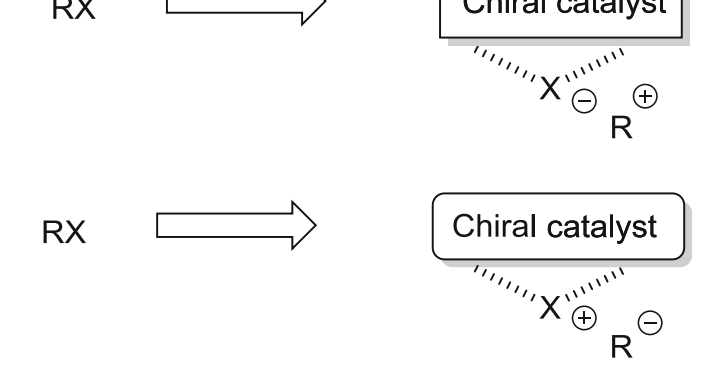

Fig. 5 Different type of chiral catalysts capable of ion-pairing

Catalysts based on designed hydrogen-bond donor groups are embracing weak interactions. Through these interactions the catalysts are able to induce ion-pairing. These interactions are inherently less directional making the transmission of the chiral information by the catalyst 
Fig. 6 Chiral catalysts used as chiral counter ions<smiles>C=CC1CN(Cc2ccccc2)CC1[C@H](O)c1ccnc2ccccc12</smiles><smiles>[R]c1ccc2cc([R])c(OP(=O)([O-])Oc3c([R])cc4ccc([R])cc4c3-c3c([R])ccc4ccc([R])cc34)c([R])c2c1</smiles><smiles></smiles><smiles>[R]c1ccc2cc(O[N+](=O)[O-])c(-c3c(OP(=O)(Oc4c([R])cc5ccc([R])cc5c4[R])O[N+](=O)[O-])c([R])cc4ccc([R])cc34)cc2c1</smiles><smiles>[R]N(C)C(=O)[C@@H]([13CH])NC(=O)Nc1cc(C(F)(F)F)cc(C(F)(F)F)c1</smiles><smiles>[X]C(NC(C(=O)N([R12])C)C(C)(C)C)N[C@@H]1CCCC[C@@H]1[X]</smiles>

Scheme 1 Azolium enolate obtained by carbene precursors an hard task. However, by the recognition of key elements the design of these catalysts has obtained extraordinary success, by combining elements capable of inducing specific attractive or repulsive interactions in the step in which the stereoselective information is transferred. Of course, there is a quite strict connection between this activation mode and the way in which substrates are activated by enzymes [35]. Also in this field "privileged" [36] structures of small molecules emerged (Fig. 6). In the review we will illustrate the design principles and the structural importance of the elements present in the catalysts, in the case of activation of iminum ions.

\subsection{Carbene Catalysis}

$N$-heterocyclic carbenes (NHCs, 7) have been extensively employed since their discovery as catalysts for $\mathrm{C}-\mathrm{C}$ bondforming reactions [37]. In organocatalytic reactions with ketenes, aldehydes, and esters they give rise to the formation of azolium enolates equivalents of ester enolates (Scheme 1) [38]. Such enolates are generally generated in situ and they are very useful nucleophiles in many reactions [39].

The nucleophilicity values of the NHCs were measured by Mayr [40] and do not differ from those of other organocatalysts (DABCO, DMAP, $\mathrm{Ph}_{3} \mathrm{P}$ ). However, these 
Scheme 2 Alkylation of isoquinolinium salts promoted by the organocatalyst $\mathbf{1 0}$

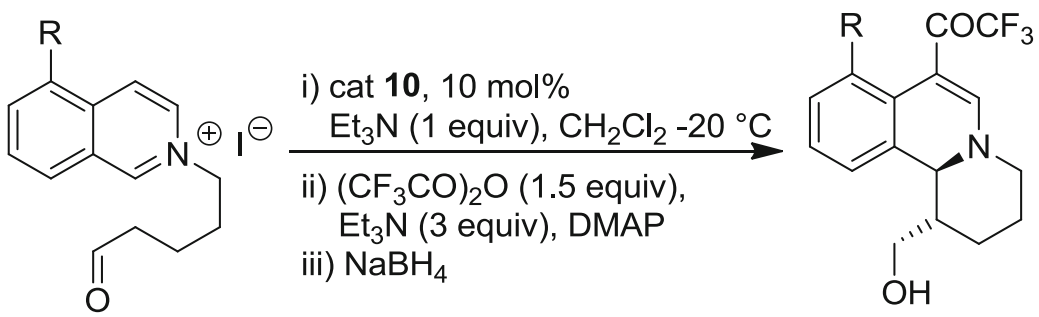

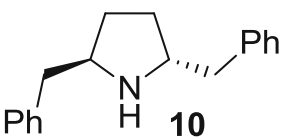

11a; $41 \%$, dr 15:1 (trans:cis), ee $92 \%$ $11 b ; 40 \%$, dr $24: 1$ (trans:cis), ee $92 \%$ 11c; $38 \%$, dr 36:1 (trans:cis), ee $93 \%$ nucleophilicity differences are crucial when they are evaluated for organocatalytic reactions. For example, the triazolylidene compound $\mathbf{7 c}$ has a considerably lower nucleophilicity compared with the imidazolylidene $\mathbf{7 b}$, caused by the inductive electron withdrawal due to the extra nitrogen in the triazole ring. All NHCs are significantly stronger Lewis bases than $\mathrm{PPh}_{3}$, DMAP, and DABCO. Saturated NHCs like 7a are rarely used as organocatalysts and this was explained by Mayr, taking into account the nucleophilicity order of the deoxy-Breslow intermediates [41]. By using the rule of thumb that combination of electrophile-nucleophile may give positive reactions at room temperature when $\mathrm{E}>-5$, and considering that the $\mathrm{N}$ values for the enolate carbon of the azolium enolates 8 are between 14.4 and 15.9, it is possible to predict that they will react with $N$-activated imines $(-11.5>\mathrm{E}>-15.1)$ and iminium ions $(\mathrm{E}=-10)$.

\section{Organocatalytic Addition of Nucleophiles to Isoquinolinium Ions}

The isoquinoline framework is present in a large number of naturally occurring and synthetic biologically active 1,2dihydroisoquinolines and the closely related 1,2,3,4-tetrahydroisoquinolines derivatives [42]. One of the recurring features of these compounds is the presence of a stereogenic center located adjacent to the nitrogen atom (Fig. 1). As we have briefly commented catalytic stereoselective synthetic methodologies for the formation of chiral isoquinoline derivatives was only described in few approaches [43]. The pioneering use of organocatalysis employing chiral $\mathrm{C}_{2}$-symmetric secondary amines for the diastereoand enantioselective annulation reaction of 2-(5-oxopentyl)isoquinolinium 9 was described by Jørgensen [44]. The key concepts studied in this work were the use of isoquinolinium salts [45] in combination with the enamine catalysis. This reaction gives rise to the formation of optically active 1,2-dihydroisoquinoline derivatives $\mathbf{1 1}$ that contain two adjacent stereocenters together with a carbonyl group suitable for further chemical transformations. The substrates for the intramolecular annulations reaction are stable isoquinolinium salts. (Scheme 2).

Quite remarkably it was reported that the corresponding intermolecular reaction, activating isoquinoline with ethyl chloroformate in presence of 3-methylbutyraldehyde and various organocatalysts, gave low yield and stereoselectivity. No further details are furnished, but probably the ethyl chloroformate is deactivating the organocatalyst by formation of the corresponding carbamate. In addition, as we have previously noted, the appropriate organocatalyst needs to be employed, because of the quite low electrophilicity of the iminium salt. Indeed Jørgensen is using chiral $\mathrm{C}_{2}$ symmetric pyrrolidine $\mathbf{1 0}$ for the reaction. Nucleophilicity of the enamines obtained with this organocatalyst are in the same order to those obtained with I-III (Scheme 2). As in the catalytic cycle iodidridic acid (HI) is formed as by-product, it is necessary to use a base $\left(\mathrm{Et}_{3} \mathrm{~N}\right)$ in order to recycle the catalyst. It is also worth mentioning that the products are quite unstable and were isolated after trifluoroacetylation and reduction. The optimized conditions for the catalytic diastereo- and enantioselective reaction gave good to high conversions (70-100\%), high diastereoselectivity (up to 98:2) and excellent enantioselectivity (85-96\% ee) for neutral or electron-poor substrates. No further transformation of the products to alkaloids or natural products were described in the paper.

Cozzi and co-workers [46] recently described the activation of various isoquinolines 12 by $\mathrm{Boc}_{2} \mathrm{O}$ or $\mathrm{CbzCl}$ in an organocatalytic alkylation promoted by the organocatalyst ent III (Scheme 3).

An important key feature of the process is the slow addition of the activating agent that is avoiding the acylation of the catalyst. The scope of the reaction is broad respect to isoquinolines and aldehydes, and the products $\mathbf{1 3}$ were isolated in moderate yields after reduction, avoiding further reaction. The Boc or $\mathrm{Cbz}$ adduct can be easily deprotected and transformed in useful intermediates. The major diastereoisomer was obtained in syn or anti configuration in function of the reaction solvent, giving the 
Scheme 3 Activation of isoquinoline by $\mathrm{CbzCl}$ and total synthesis of a protoberberine alkaloid i) ent III, $20 \% \mathrm{~mol}$

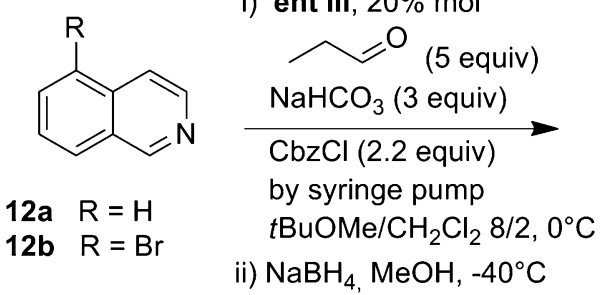<smiles>[R]c1cccc2c1C=CN(C(=O)OCc1ccccc1)[C@H]2[C@H](C)CO</smiles><smiles>[R]c1cccc2c1C=CN(C(=O)OCc1ccccc1)[C@H]2[C@H](C)CO</smiles>

13a; 53\%, dr 74:26 (syn:anti), ee syn $96 \%$ 13b; 40\%, dr 77:23 (syn:anti), ee syn $95 \%$

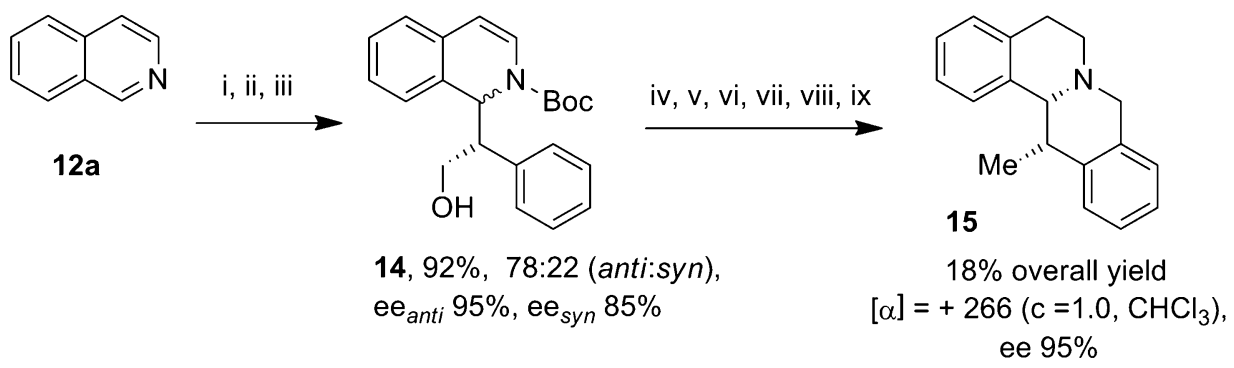

i: $\mathrm{Boc}_{2} \mathrm{O}, \mathrm{DCM}, \mathrm{rt}$

ii: ent III, $100 \% \mathrm{~mol}$ $\mathrm{Ph}=\mathrm{O}$ (3 equiv)

$\mathrm{DCM}, 0^{\circ} \mathrm{C}$

iii: $\mathrm{NaBH}_{4}, \mathrm{MeOH}, 0^{\circ} \mathrm{C}$

iv: $\mathrm{H}_{2}, \mathrm{Pd} / \mathrm{C}, \mathrm{MeOH}$, rt; chromatographic separation

v: $\mathrm{CH}_{3} \mathrm{COSH}, \mathrm{DEAD}, \mathrm{PPh}_{3} \mathrm{THF}, 0^{\circ} \mathrm{C}$ to $\mathrm{rt}$

vi: Ni/Raney, THF, rt, then TFA, DCM, rt

vii: triphosgene, DIPEA, rt

viii: $\mathrm{AlCl}_{3}$, toluene, $110^{\circ} \mathrm{C}$

ix: $\mathrm{LiAlH}_{4}, \mathrm{THF} / \mathrm{Et}_{2} \mathrm{O}, 0^{\circ} \mathrm{C}$ to rt

of enantiopurity. As illustrated in Scheme 4 the catalyst acts by hydrogen bonding interactions with the chloride ion formed by the activation of the isoquinoline ring.

Chiral silane diols were also able to act in anion-binding catalysis as reported by Matteson [50]. The enantiomeric excess obtained in the similar reaction of silyl ketene acetals with $\mathrm{N}$-acylisoquinolinium ion was still quite unsatisfactory and limited to isoquinoline substituted with electron-withdrawing groups. However, the concept is quite interesting and worth to be further exploited.

Isoquinolinium intermediates can alkylated by azaenolethers in presence of a chiral hydrogen-bonding catalyst [51] as reported by Seidel. Both electrophilic and nucleophilic reaction partners are generated in situ by the efficient Steglich [52] rearrangement of $O$-acylated azalactone (Scheme 5).

The reactions were conducted in mixtures of mesitylene and pentane at $-25{ }^{\circ} \mathrm{C}$. The best result was obtained with a 1:2 mixture of mesitylene and pentane, in the presence of the thiourea catalyst $\mathbf{1 8}$. Various $O$-acylated azalactones derived from different amino acids were reactive in the reported conditions furnishing the products 19 in generally high yields and levels of enantio- and diastereoselectivity with a number of differently substituted isoquinolines [53]. 
Scheme 4 Acyl Mannich reaction of substituted isoquinolines
Scheme 5 Addition of azlactones to isoquinolines promoted by the thiourea catalyst

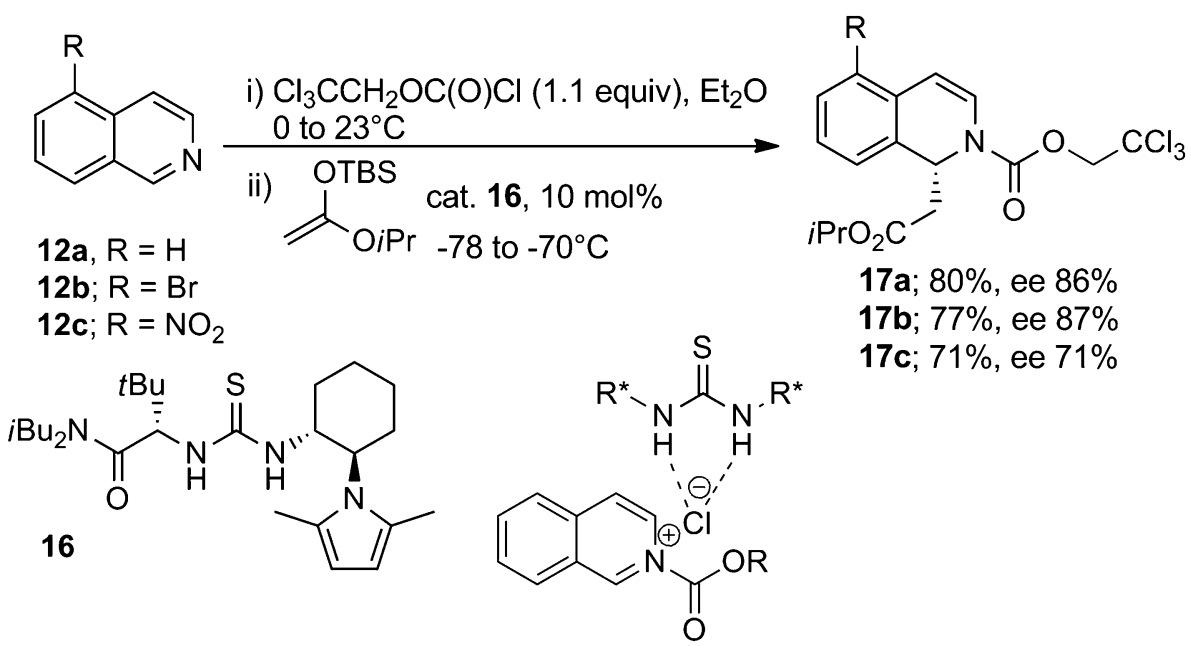

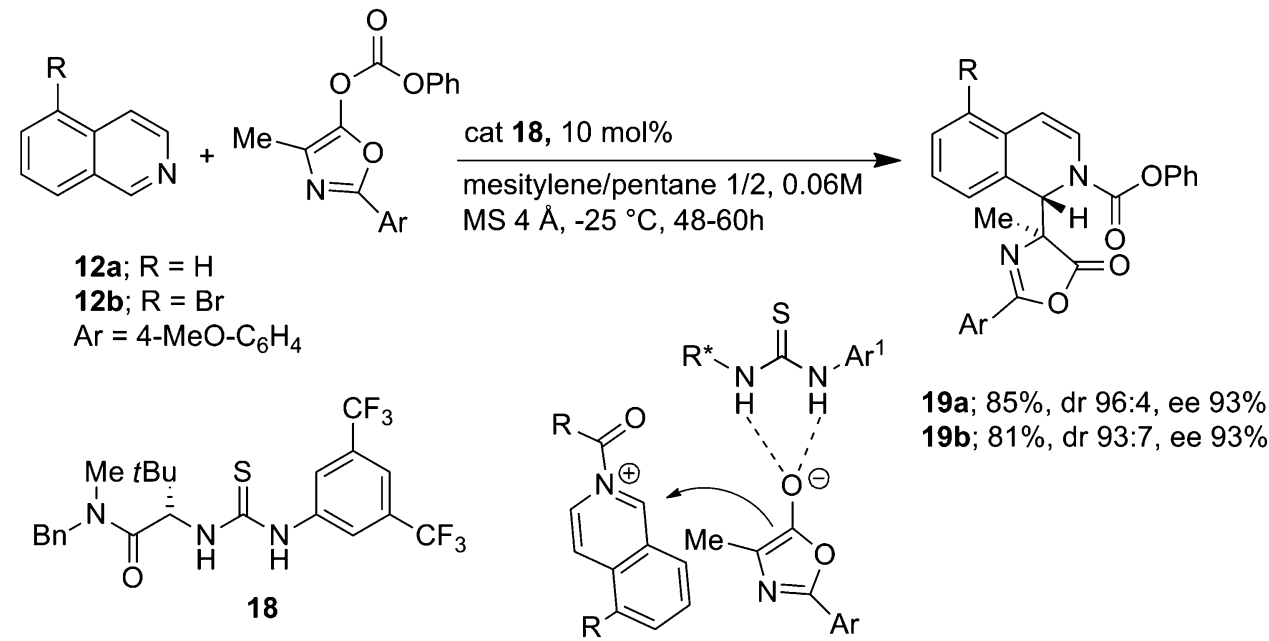

\section{Organocatalytic Addition of Nucleophiles to Dihydroisoquinolinium Iminium Ion}

\subsection{Stereoselective Dehydrogenative Cross Coupling}

The cross-dehydrogenative coupling (CDC) reaction has been extensively investigated in the last decade [54]. Various methods have been described for the generation via oxidative process of an iminium activated specie [32], formed from a tetrahydroisoquinoline derivative, but in most of the published procedures, the nucleophilic attack was not stereoselective, even when proline or proline derivatives were used as organocatalysts [55-57]. The first successful example of addition of chiral nucleophiles (enamines) through cross dehydrogenative coupling was reported by Chi [58]. As it was well discussed by Klussmann, the oxidation of $\mathrm{N}$-aryltetrahydroisoquinolines $\mathbf{2 0}$ forms an electrophilic iminium derivative. Chi used a combination of tert-butylhydroperoxide in the presence of
$\mathrm{CuBr}_{2}$ to perform the oxidation, and the reaction was catalysed by the Jørgensen diarylprolinol catalyst III (Scheme 6). We have previously remarked that the enamines formed by III are more nucleophilic than the ones obtained with the other organocatalysts, and their use is related to the low electrophilicity of 6 (Fig. 4).

The products were obtained in $31-71 \%$ yield but with low diastereoselectivity, although the enantioselectivity was in general quite good. The aldehyde compounds, as the adducts obtained by Jørgensen [44], suffered of low stability, and they were reduced to their corresponding alcohols to avoid racemization and decomposition. Although the authors reported the use of 4-MeO- $\mathrm{C}_{6} \mathrm{H}_{4}$ (PMP) as aryl group (20b), they did not report an effective procedure for its cleavage. This appears a limitation in the methodology. The procedure was extended to the addition of ketones by the work of Wang and co-workers [59]. $\mathrm{N}$-aryl tetrahydroisoquinolines $\mathbf{2 0}$ were coupled with cyclic ketones with $L$-phenylalanine as chiral catalyst in the presence of 


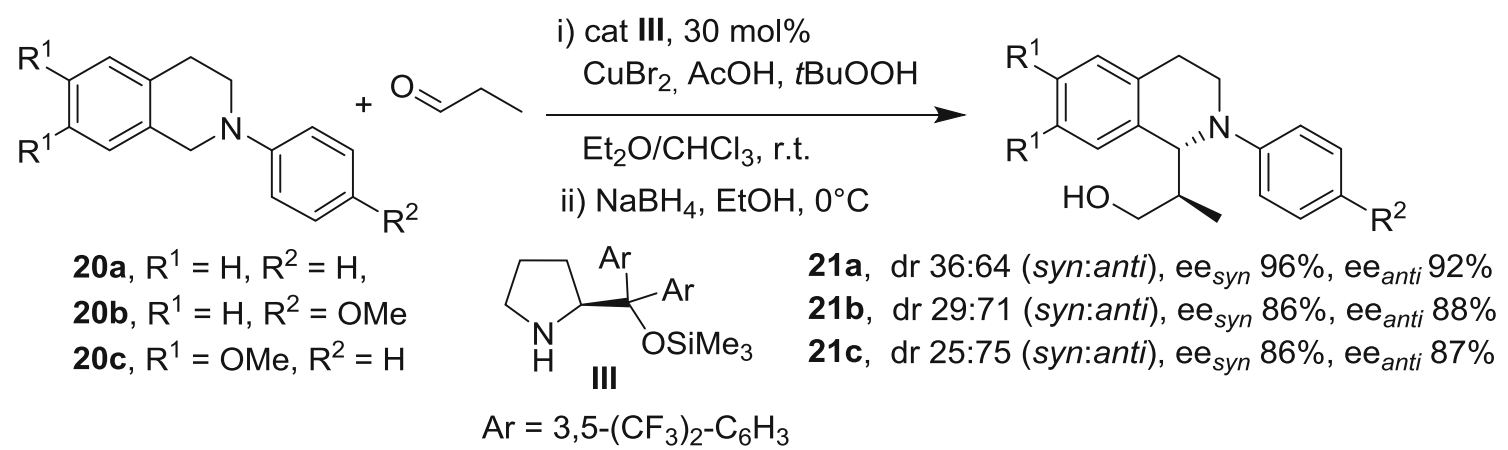

Scheme 6 Dehydrogenative stereoselective coupling catalysed by Jørgensen catalyst III

Scheme 7 Catalytic enantioselective oxidative cross-dehydrogenative coupling of tetrahydroisoquinolines to ketones
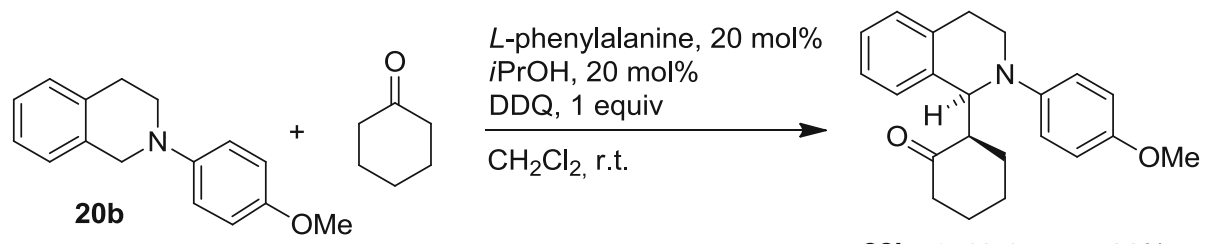

22b, dr 13:1, ee syn $90 \%$<smiles>C/C=C/C(C)C</smiles><smiles>COc1ccc(N2CCc3ccccc3C2)cc1</smiles>

cat 23, $20 \mathrm{~mol} \%$<smiles>C=CC(C)=O</smiles>
$\mathrm{Cu}(\mathrm{OTf})_{2,}, 10 \mathrm{~mol} \%$ $\mathrm{O}_{2}, 1 \mathrm{~atm}$ $\mathrm{MS} 4 \AA, \mathrm{Na}_{2} \mathrm{SO}_{4}$, $\mathrm{CH}_{2} \mathrm{Cl}_{2}, 36 \mathrm{~h}$<smiles>C=CC1CN2CCC1C2[C@H](O)c1ccnc2ccc(OC)cc12</smiles><smiles>C=C(C(C)=O)C1c2ccccc2CCN1c1ccc(OC)cc1</smiles>

$24,72 \%$, ee $90 \%$

Scheme 8 Enantioselective dehydrogenative coupling of tetrahydroisoquinoline with unsaturated alkenes

anhydrous $i \mathrm{PrOH}$ as additive, and 2,3-dichloro-5,6-dicyanoquinone (DDQ) as oxidant (Scheme 7). The scope of the reaction was tested with different substrates, and the reaction proceeded well to afford the products in good yields and from good to excellent diastereo- and enantioselectivities. The use of ketones was limited to cyclohexanone derivatives, while the $N$-aryl group was varied considerably. The absolute and relative configuration of the newly formed stereocenters was firmly established by $\mathrm{X}$-ray analysis.

The possible reaction mechanism is illustrated in Scheme 7. For many of the transformation discussed in this section a single-electron transfer (SET) induced by DDQ is assumed [60]. Quenching experiment with 2,6-di-tertbutyl-4-hydroxytoluene (BHT) were reducing the yield of the coupling showing the probable presence of radical cation. Wang also explored the possibility of using cooperative organocatalysis in a different reaction describing an aerobic oxidative aza-Baylis-Hillman reaction of $\mathrm{N}$-aryltetrahydroisoquinolines 20 (Scheme 8) [61].

The oxidation was carried out with a combination of $\mathrm{Cu}(\mathrm{OTf})_{2}$ and $1 \mathrm{~atm}$ of molecular $\mathrm{O}_{2}$ as oxidant system, and quinine $\mathbf{2 3}$ was used as the catalyst. For this reaction the scope was quite large concerning the $N$-substitution of 
Scheme 9 Enantioselective cross dehydrogenative intramolecular coupling of tethered tetrahydroquinoline promoted by chiral traizolecontaining phosphoric acid

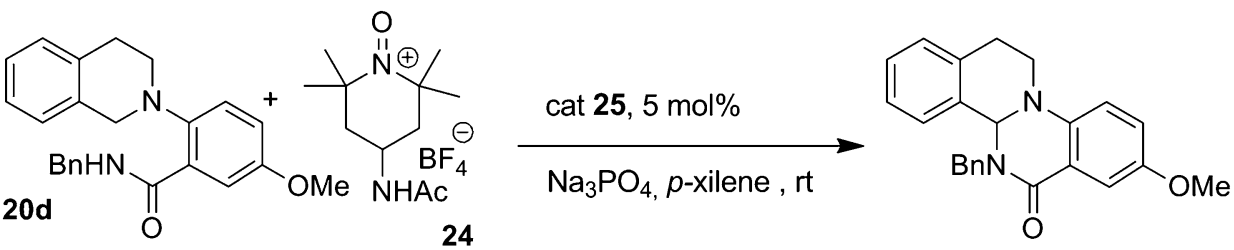

26, $83 \%$, ee $84 \%$

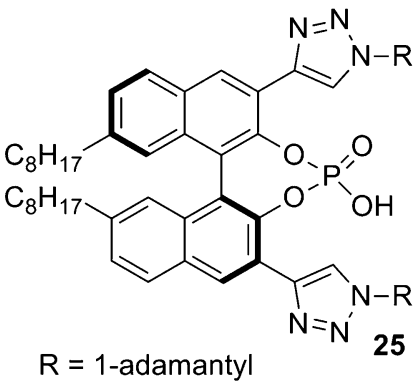

25

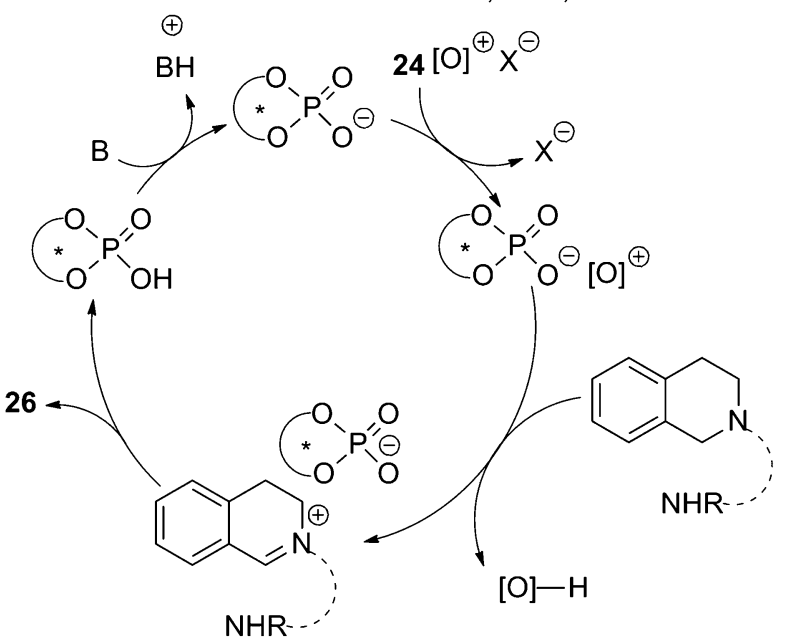

tetrahydroisoquinolines. The desired products were obtained in 47-82\% yields and 69-99\% enantiomeric excess for the reaction with various olefins. The presence of methoxy groups on the 6,7-position or chlorine on the 7-position of the tetrahydroisoquinoline ring did not influence the reaction outcome. Methylvinylketone and acrylonitrile were also tested giving excellent results. The absolute configuration of a key product was established by single-crystal X-ray diffraction, and the configuration of the others adducts was established by analogy. The deprotection or application of these products as key intermediates in synthesis was not disclosed. Toste applied the chiral counter anion catalysis in an example in which he described the synthesis of a $\mathrm{C}-\mathrm{N}$ bond-forming reaction to produce 1,2,3,4-tetrahydroisoquinoline-derived cyclic aminals [62]. The stereoselective reaction is promoted by the formation of a chiral phosphate that undergoes anion exchange with an appropriately chosen cationic oxidant. The generation of the iminium by oxidation and the subsequent anion exchange allows the formation of a tight chiral ion-pair. The phosphate chiral catalyst is re-generated after the nucleophilic addition (Scheme 9).

Amide-tethered tetrahydroisoquinoline 20d are cyclized in the presence of the oxoammonium salt 24. A careful design of the chiral phosphoric acid was necessary in order to achieve good selectivity. The guide principle was the inspection of the needs to perform a reaction with such chiral Brønsted acids. In first instance, a bulky group needs to be installed in $3,3^{\prime}$ positions of the BINOL backbone.
As in this case the presence of bulkyness was not enough to guarantee a good stereoselection, an "enzyme like" secondary interaction with substrate was introduced in the catalyst design. The 1,2,3-triazole moiety was chosen because of its ability to perform hydrogen bond together with its modularity and facile introduction by click chemistry [63]. A series of 3,3'-triazolyl-BINOL-phosporic acids 25 were prepared and evaluated for the reaction, and through the fine tuning of the catalyst structure, excellent enantioselectivities and conversions were observed. The enantioselective oxidative $\mathrm{C}-\mathrm{H}$ functionalization of tetrahydroisoquinoline derivatives can be achieved by the use of another powerful concept. Organocatalytic photoredox catalysis has been quite recently introduced by the pioneering work of MacMillan [64] and photocatalytic transformations emerged recently as a powerful tool for organic synthesis [65]. Two key transformations were recently described in which the stereoselective addition of chiral nucleophiles to tetrahydroisoquinolines is achieved through photocatalysis. The first report is the combination of photoredox catalysis with $N$-heterocyclic carbene catalysis developed by Rovis [66]. In the introductive section, we have highlighted the role of carbene catalysis in the generation of acyl anion or homoenolate equivalents from aldehydes under very mild conditions. These species have been demonstrated to be competent nucleophiles in a large variety of reactions $[67,68]$. The nucleophilicity of carbene enolates measured by Mayr is sufficient for the reaction with iminium intermediates, and the possibility of 


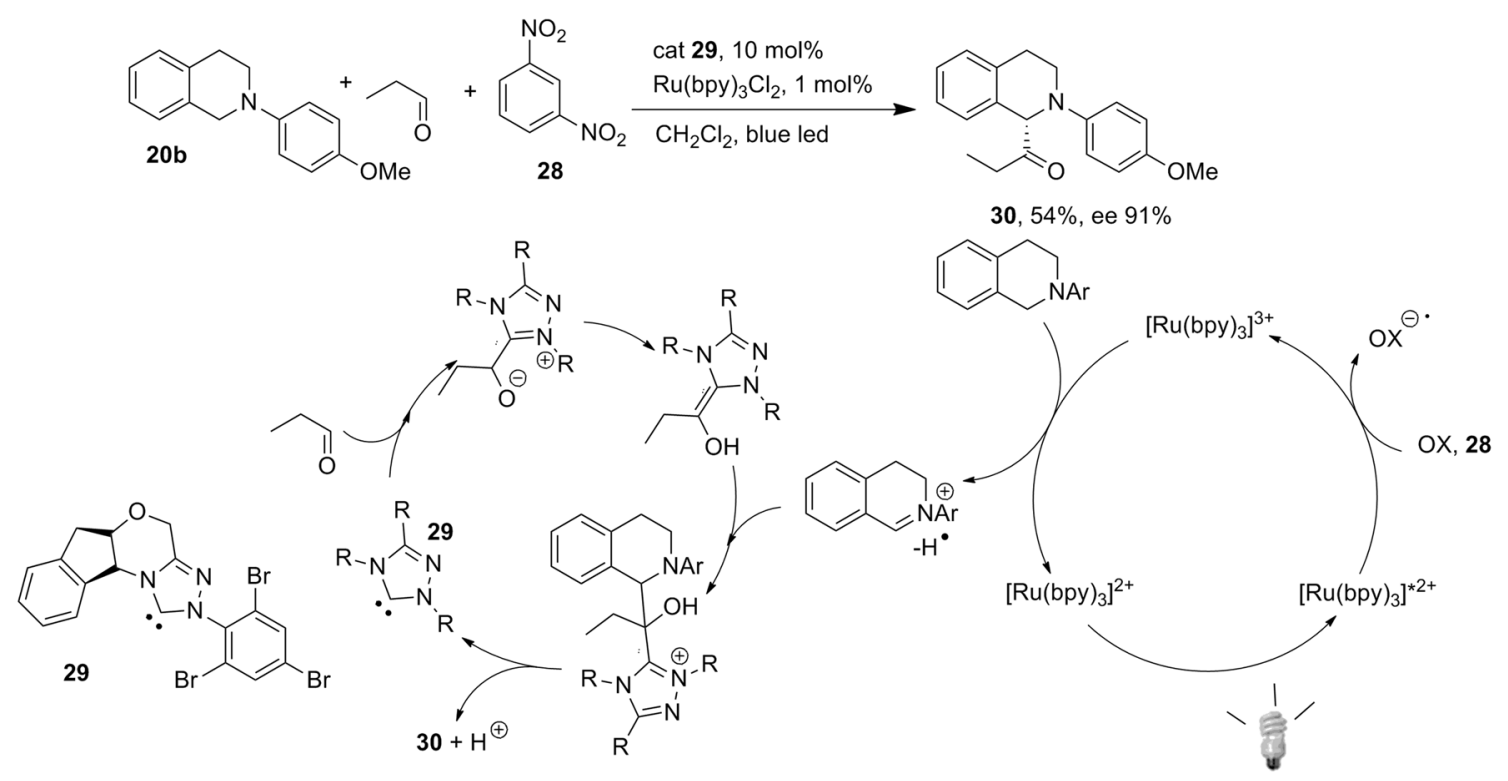

Scheme 10 Asymmetric acylation of tetrahydroisoquinoline mediated by photoredox catalysis in the presence of a chiral carbene

the reaction is quite predictable. However, the difficulties in the oxidative coupling is determined by the possibility to oxidize the Breslow intermediate to unproductive pathways [69]. As illustrated in Scheme 10, the irradiation of $\left[\mathrm{Ru}(\mathrm{bpy})_{3}\right]^{2+}$ with blue light populates the $\left[\mathrm{Ru}(\mathrm{bpy})_{3}\right]^{*^{2+}}$ excited state, giving rise to a powerful oxidant or reductant. If the oxidant $\left[\mathrm{Ru}(\mathrm{bpy})_{3}\right]^{3+}(1.29 \mathrm{~V}$ vs SCE) is generated by reduction of an oxidative quencher, this specie is capable of a single-electron oxidation of a $\mathrm{N}$-aryl tetrahydroisoquinoline, giving after hydrogen atom abstraction, a radical intermediate that is further oxidazed to the activated iminium. This electrophile is then intercepted by the nucleophylic Breslow intermediate obtained by reaction of the aldehyde with the carbene catalyst.

The reaction is possible using $\left[\mathrm{Ru}(\mathrm{bpy})_{3}\right] \mathrm{Cl}_{2}$ as the photocatalyst in the presence of $m$-dinitrobenzene $(\mathrm{m}$ DNB) 28 as the oxidant and chiral NHC 29 under irradiation with blue light. A careful optimization of the catalyst was necessary, giving optimal yields and high enantioselectivity (92\% ee) for a series of various functionalized $\alpha$ amino ketones.

Irradiation of photoactive catalysts and asymmetric anion-binding catalysis can also be merged in a quite interesting and innovative process. Jacobsen and Stephenson have described the stereoselective addition of not prochiral silyl ketene acetal to isoquinoline by the use of chiral anion-binding catalysts in combination with photocatalysis (Scheme 11). In this transformation the photocatalysed oxidation is generating a reactive specie that is trapped by a chiral H-bond donor catalyst, chiral thiourea
31. The stoichiometric oxidant that is used in this reaction is $\mathrm{CCl}_{4}[70]$.

The reaction is realized in two steps: in the first one the formation of a stable iminium is achieved by the use of photocatalysis in a polar solvent $(\mathrm{MeCN})$ that allows the solubilisation of the photocatalyst. Then the solvent is switched to $t \mathrm{BuOMe}$ for the stereoselective reaction conducted at low temperature. Unfortunately electron rich dehydroisoquinoline are affording moderate to low enantiomeric excesses. Instead of many papers published on this subject, the authors were able to describe a new protocol for $\mathrm{N}$-dearylation of the products to provide derivatives that could be used in alkaloid synthesis. The ortho methoxy derivative was deprotected in good yield by the use of a specific reagent, $\left.\left[\mathrm{Fe}(\mathrm{bpy})_{3}\right]\left(\mathrm{PF}_{6}\right)_{2}\right]$. Application of other standard oxidative protocol (CAN, PhI(TFA $)_{2}$, or DDQ) led to low yields or extensive decomposition via overoxidation.

\subsection{Pictet-Spengler Via Hydrogen Bond Activation}

The Pictet-Spengler reaction was discovered in 1911 and it is now widely used for the synthesis of a large variety of heterocyclic compounds named alkaloids [71]. The first enantioselective catalytic Pictet-Spengler reaction was described by Jacobsen (Scheme 12) [72]. Formation of the reactive acyliminium is realized in situ by activation with $\mathrm{AcCl}$. After a careful optimization of the structure of the catalyst and of the reactions conditions the methodology was applied to a series of aliphatic aldehydes, giving the desired products in good yields and stereoselectivity. Unfortunately the 


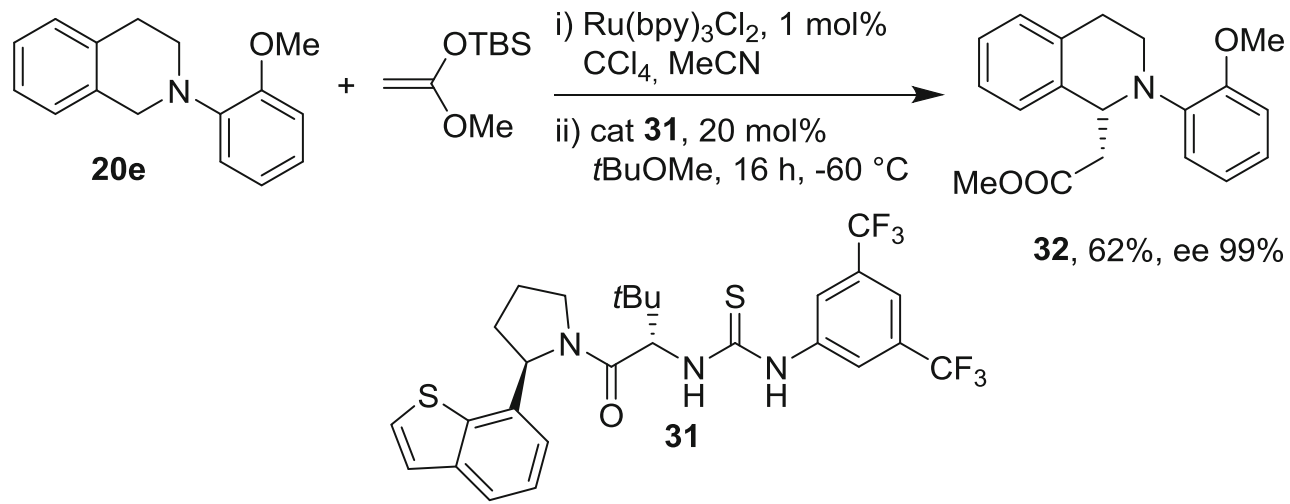

Scheme 11 Photocatalytic reaction of isoquinoline with a silyl ketene acetal promoted by a chiral thiourea catalyst

Scheme 12 Asymmetric acyl Pictet-Spengler reaction catalysed by chiral thiourea catalyst $\mathbf{3 3}$<smiles>[R]c1ccc2[nH]cc(CCN)c2c1</smiles>

$34 a, R=H$

34b, $\mathrm{R}=\mathrm{OMe}$

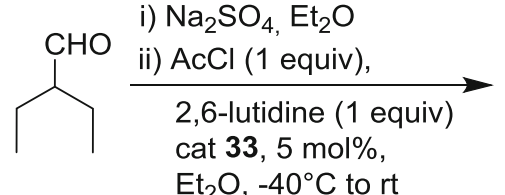

$\mathrm{Et}_{2} \mathrm{O},-40^{\circ} \mathrm{C}$ to $\mathrm{rt}$<smiles>CCCCNC(=O)[C@H](CC(C)C)NC(=O)N[C@H]1CCCC[C@H]1n1c(C)ccc1-c1ccccc1</smiles><smiles>[R]c1ccc2[nH]c3c(c2c1)CCN(C)[C@H]3C(CC)CC</smiles>

35a, $\mathrm{R}=\mathrm{H}, 65 \%$, ee $93 \%$ 35b, $R=$ OMe, $81 \%$, ee $93 \%$
Scheme 13 Asymmetric cyclization of the hydroxyl lactam 37 promoted by the thiourea catalyst $\mathbf{3 6}$<smiles>[R]c1ccc2[nH]cc(CCN3C(=O)CC[C@@H]3O)c2c1</smiles>

$37 \mathrm{a}, \mathrm{R}=\mathrm{H}$

37b, $\mathrm{R}=\mathrm{OMe}$<smiles>[R]c1ccc2[nH]cc(CCN3C(=O)CCC3=O)c2c1</smiles>

key intermediate<smiles>Cc1ccc(-c2ccccc2)n1[C@@H]1CCCC[C@H]1NC(=S)NC(C(=O)N([14CH3])[14CH3])C(C)(C)C</smiles>

36 cat 36 (10 mol\%), TBMSCI,

TBME, $-78^{\circ} \mathrm{C}$, 24-72 h<smiles>[R]c1ccc2[nH]c3c(c2c1)CCN1C(=O)CC[C@H]31</smiles>

38a, $\mathrm{R}=\mathrm{H}, 90 \%$, ee $97 \%$

38b, R = OMe, $86 \%$, ee $95 \%$<smiles>c1ccc2c3c([nH]c2c1)[C@H]1CCCN1CC3</smiles>

(+)-harmicine 39 stereoselective variants of the Pictet-Spengler reaction are limited to tryptamine and tryptamine derivatives $\mathbf{3 4}$.

Jacobsen disclosed an enantioselective variant of the Pictet-Spengler reaction of 3-indolyl-tethered hydroxylactams catalysed by chiral thiourea 36. The cationic $N$ - acyliminum intermediate was obtained after the treatment of hydroxylactam 37 with TMSCl (Scheme 13) [73].

The chlorolactam intermediate in the presence of the thiourea afforded an ion pair catalyst complex after a chloride dissociation induced by the catalyst. Thus the 
Scheme 14 Thiourea and benzoic acid catalysed PictetSpengler reaction with activated tryptamines<smiles>COc1ccc2[nH]cc(CCN)c2c1</smiles><smiles>O=Cc1ccc(Cl)cc1</smiles>

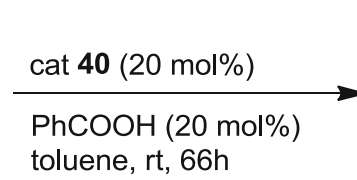

toluene, rt, $66 \mathrm{~h}$ 34b<smiles>CC(C)C(NC(=S)Nc1cc(C(F)(F)F)cc(C(F)(F)F)c1)C(=O)N(Cc1ccccc1)C(F)(F)F</smiles><smiles>COc1ccc2[nH]c3c(c2c1)CCN[C@H]3c1ccc(Cl)cc1</smiles>

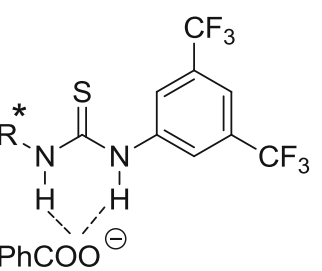<smiles>COc1ccc2[nH]cc(CC[NH+]=Cc3ccc(Cl)cc3)c2c1</smiles>

anion binding properties of the thiourea catalyst are quite important for activating the chlorolactam substrate. In a kinetic analysis performed on the episulfonium opening reaction [74] Jacobsen was able to indicate the rate determining step, that was the enantio-determining step as well. The conclusions highlighted in the paper can be translated to other reactions promoted by chiral thiourea catalysts. Thiourea catalysts are able to stabilize an anion by binding, and to activate the nucleophilic indole via a catalyst amide-indole $\mathrm{N}-\mathrm{H}$ interaction. Thioureas possessing donating aromatic groups, such as the catalyst $\mathbf{3 6}$, are able to stabilize the transition state through a cation- $\pi$ interaction with the aromatic ring. The cyclized products were obtained in yields of 51-94\% with ees ranging from 81 to $99 \%$. In particular by the use of this methodology, the alkaloid (+)-harmicine 39 was prepared in four steps from tryptamine in $62 \%$ overall yield and $97 \%$ ee. However, the reaction was limited to the use of aliphatic aldehydes.

A careful design of the catalyst allowed the development of an enantioselective catalytic Pictet-Spengler reaction with a broad substrate scope for tryptamines [75]. Under the optimized reaction conditions, with simple catalyst 40 prepared in three steps, a series of substituted benzaldehydes were condensed. The presence of a suitable Brønsted acid, namely benzoic acid in catalytic amount $(20 \mathrm{~mol} \%)$ is important in order to promote the reaction with aromatic aldehydes (Scheme 14). The reaction rate was enhanced by the use of electron rich tryptamines.

List and co-workers in 2006, observing that the catalytic Pictect-Spengler was assumed to involve chiral, hydrogenbond assisted iminium ion pairs, explored the use of phosphates as chiral anions [76]. Taking advantage of the Thorpe-Ingold effect for forcing the cyclization they used a tailored geminal disubstituted tryptamine substrates in the presence of a chiral organic Brønsted acid (Scheme 15).
They found that the chiral phosphoric acid 43, now called TRIP, gave the highest enantioselectivity in the PictetSpengler cyclisation. The reaction was effective with aliphatic and aromatic aldehydes affording the desired products in good yields and ees varying from 62 to $96 \%$.

The presence of geminal substituents to allow the cyclization was found unnecessary by Hiemstra, that described Pictet-Spengler reactions of $N$-sulfenyl 45a [77] and benzyl 45b [78] tryptamines (Scheme 16).

The bulkier $N$-tritylsulfenyl group requires careful conditions and the presence of radical scavenger (3,5di(tert-butyl)-4-hydroxytoluene, BHT) and molecular sieves. It is important to point out that a different phosphoric acid is here necessary to reach good level of stereoselectivity, pointing out the delicate balance of steric and electronic effects in these reactions. The obtained products were directly deprotected in a one-pot procedure. The enantiomeric excesses obtained with aromatic and aliphatic aldehydes were however in the range between 72-86 \%. In the case of benzyl triptamines [77] the enantiomeric excesses obtained were above $80 \%$ for $p$-substituted aromatic aldehydes. The catalyst that gave the highest selectivity in this case was 3,3'-triphenylsilyl substituted phosphoric acid 46a. This approach was used by Hiemstra in the total synthesis of alkaloids. The catalyzed PictetSpengler reaction of the derivative 48 with methyl 5-oxo-2(phenylseleno)pentanoate in the presence of phosphoric acid 49 gave the corresponding product (Scheme 17) that was converted, by nine-steps, to (+)-yohimbine 51 [79].

Another quite interesting total synthesis of the indole alkaloids (-)-mitragynine 55, (+)-paynantheine 56 and (+)-speciogynine $\mathbf{5 7}$ was reported by Maarseveen and Hiemstra (Scheme 18) [80]. These compounds were synthesized in nine steps from 4-methoxytryptamine by enantioselective catalysed Pictet-Spengler reaction as one 


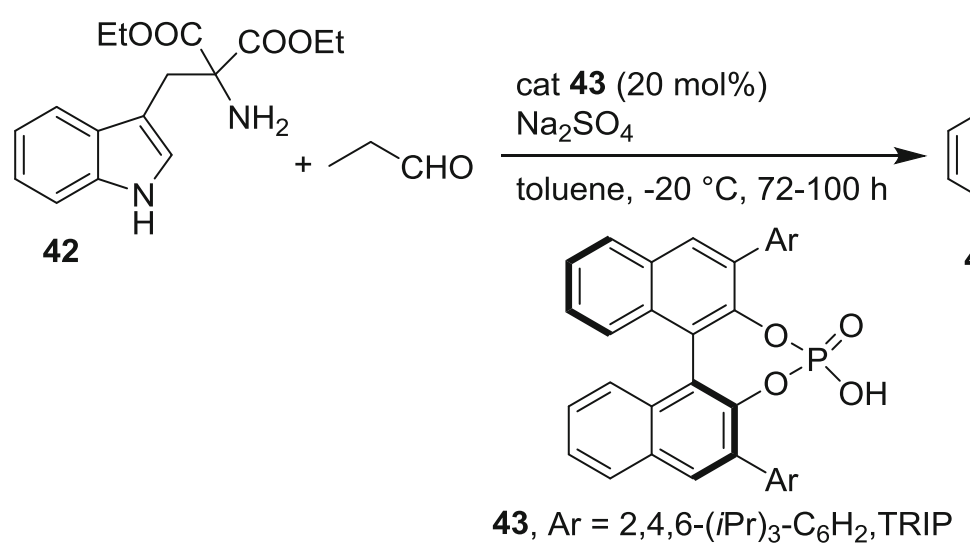

Scheme 15 Catalytic asymmetric Pictet-Spengler reaction promoted by the chiral phosphoric acid TRIP

Scheme 16 Differently protected tryptamines in effective Pictet-Spengler reaction promoted by chiral phosphoric acids

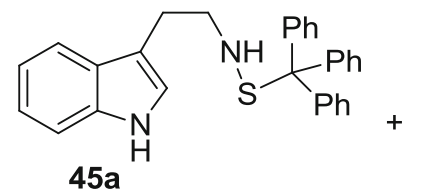<smiles>CC(C)C=O</smiles>

i) cat $46 \mathrm{a}, 20 \mathrm{~mol} \%$ MS $3 \AA$, $\mathrm{BHT}$

ii) $\mathrm{PhSH}, \mathrm{HCl}$<smiles>CC(C=O)[S+]Br</smiles>

i) cat $46 \mathrm{~b}, 2 \mathrm{~mol} \%$ MS 4A, Toluene, rt to $70^{\circ} \mathrm{C}$<smiles>[R]c1cc2ccccc2c(-c2c(O)c([R])cc3ccccc23)c1O</smiles>

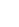
$\mathrm{P}=\mathrm{OH}$<smiles>CC(C)[C@H]1NCCc2c1[nH]c1ccccc21</smiles>

$47 a, 77 \%$, ee $78 \%$<smiles>CC(C)[C@H]1c2[nH]c3ccccc3c2CCN1Cc1ccccc1</smiles>

47b, $90 \%$, ee $81 \%$
Scheme 17 Enantioselective approach to (+)-yohimbine $\mathbf{5 1}$ through an asymmetric PictetSpengler reaction

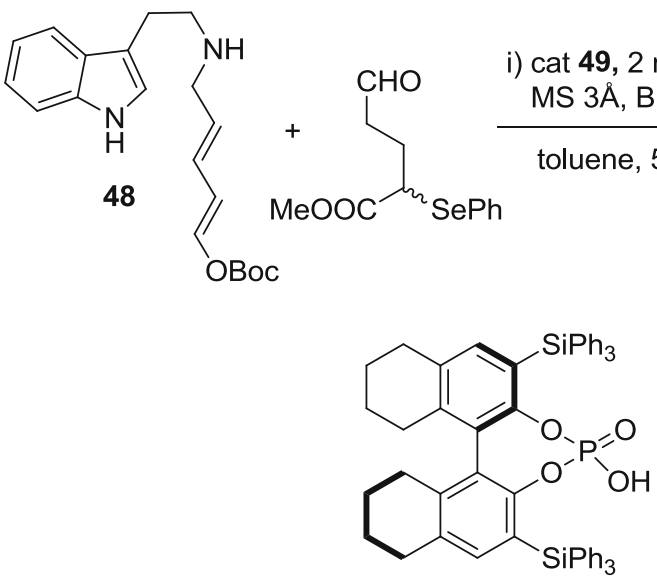

49

\section{EtOOC}<smiles>CN</smiles><smiles>C1CN1</smiles>

H

$44,76 \%$, ee $88 \%$

46a, $\mathrm{R}=3,5-\left(\mathrm{CF}_{3}\right)_{2}-\mathrm{C}_{6} \mathrm{H}_{3}$

46b, R $=\mathrm{SiPh}_{3}$ 


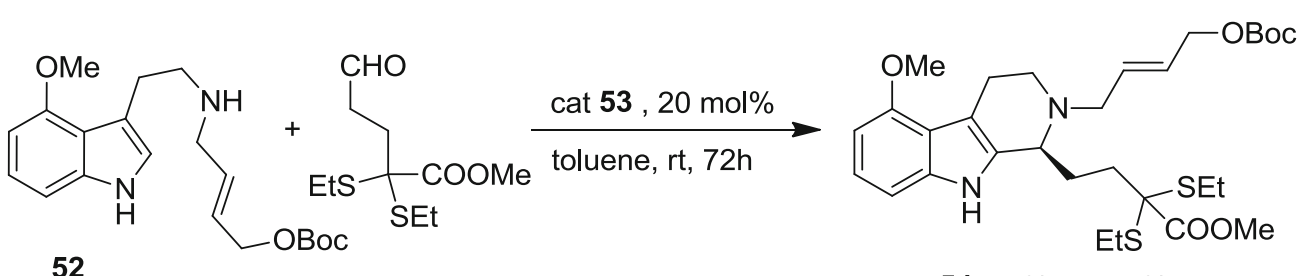

52<smiles>C=CC1CC2CCN1C([C@H](NC(=S)Nc1cc(C(F)(F)F)cc(C(F)(F)F)c1)c1ccnc3ccc(OC)cc13)C2</smiles>

$54,90 \%$, ee $89 \%$<smiles>CCC1CN2CCc3c([nH]c4ccccc34)C2CC1/C(=C\OC)C(=O)OC</smiles>

(-)-mitragynine 55<smiles>[R]C1CN2CCc3c([nH]c4ccccc34)[C@@H]2C[C@@H]1/C(=C\OC)C(C)=O</smiles>

(+)-paynantheine 56, $\mathrm{R}=\mathrm{CH}=\mathrm{CH}_{2}$

(+)-speciogynine $57, \mathrm{R}=\mathrm{Et}$

Scheme 18 A simple prepared thiourea catalyst from quinine as effective catalyst for Pictet-Spengler reactions

Scheme 19 Thiourea/benzoic acid catalyzed iso-PictetSpengler reaction<smiles>NCCc1cc2ccccc2[nH]1</smiles>

58<smiles>CC(C)(C)C(NC(=S)Nc1cc(C(F)(F)F)cc(C(F)(F)F)c1)C(=O)Nc1ccccc1</smiles>

59 of the key steps. Interestingly, in the described transformation, the structure of the alkaloids influenced the choice of the chiral catalyst employed for the Pictet-Spengler reaction. As thioureas are the catalysts of choice with more nucleophilic indole systems the authors screened commercially available catalysts and they found that a simple prepared chiral catalyst $\mathbf{5 3}$ derived from quinine was the most effective.

The one-pot condensation of isotryptamines and aldehydes that gave enantiomerically enriched 4-substituted tetrahydro- $\gamma$-carbolines was reported by Jacobsen [81] (Scheme 19).

Also in this report, a chiral thiourea 59/benzoic acid dual catalyst system was used to promote the reaction with aliphatic and aromatic aldehydes. Remarkably, also ketone substrates were successfully applied to this iso-PictetSpengler protocol. In a single example, $p$-chloroacetophenone was treated under the catalytic conditions. Even if a prolonged reaction time (14 days) is needed, the desired tetrahydro- $\gamma$-carboline $\mathbf{6 0}$ is obtained in $95 \%$ yield and $76 \%$ ee. Although in many cases the enantiomeric excesses were not excellent, simple trituration or crystallization was sufficient to rise the enantiomeric excesses.

Most of the examples reported for the organocatalytic stereoselective Pictet-Spengler reaction have been restricted to tryptamines and tryptamines derivatives. This observation is not a prise as a quick inspection in the Mayr scale can give a clear idea of the higher nucleophilicity of indole systems compared to benzene rings. In addition, the hydrogen bonding properties of the indole $\mathrm{N}-\mathrm{H}$ can improve the control in the transition state with hydrogen bond forming catalysts. Recently, Hiemstra and co-workers [82] have disclosed a remarkable result showing that a series of 1-substituted 1,2,3,4-tetrahydroisoquinolines $\mathbf{6 2}$ can be prepared from $N$-(o-nitrophenylsulfenyl)-2-phenylethylamines through $(S)$-BINOL and $(R)$-TRIP phosphoric acid $\mathbf{4 3}$ catalyzed asymmetric Pictet-Spengler reactions. By using this new methodology the natural products $(R)$ - 
Scheme 20 An effective TRIP catalyzed Pictet-Spengler reaction that gave tetraisoquinolines intermediates for the synthesis of natural alkaloids<smiles>CCCCCCCc1ccc(OC)c(O)c1</smiles>

61 cat 43 TRIP, $5 \mathrm{~mol} \%$

(S)-BINOL, $20 \mathrm{~mol} \%$

toluene $80^{\circ} \mathrm{C}, 18 \mathrm{~h}$

$$
\mathrm{Ar}=2-\mathrm{NO}_{2}-\mathrm{C}_{6} \mathrm{H}_{4} \mathrm{SO}_{2}
$$<smiles>COc1cc2c(cc1OC)[C@H]1CCCN1CC2</smiles><smiles>COc1cc2c(cc1OC)[C@H](CO)NCC2</smiles><smiles>COc1cc2c(cc1O)[C@H](CCCCOC(C)(C)C)NCC2</smiles>

$R$-(+)-calycotomine, 1d $R-(+)$-colchietine, 1e

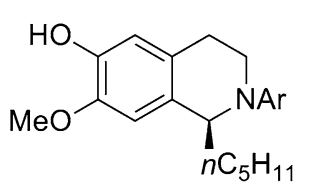

62, $88 \%$, ee $78 \%$

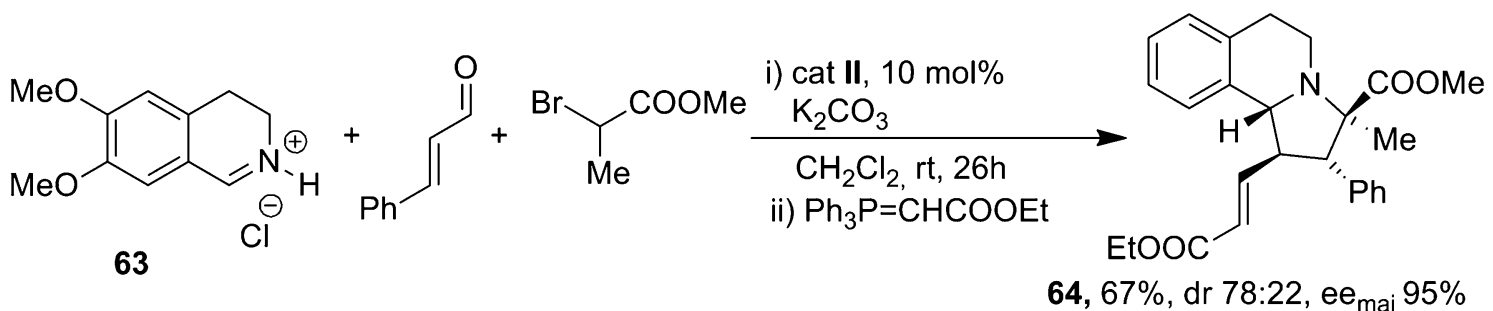

$64,67 \%$, dr $78: 22$, ee maj $95 \%$

Scheme 21 Three component reaction promoted by Jørgensen catalyst II

Scheme 22 Three component aza-Diels-Alder reaction of indole promoted by oxetane containing aldehyde

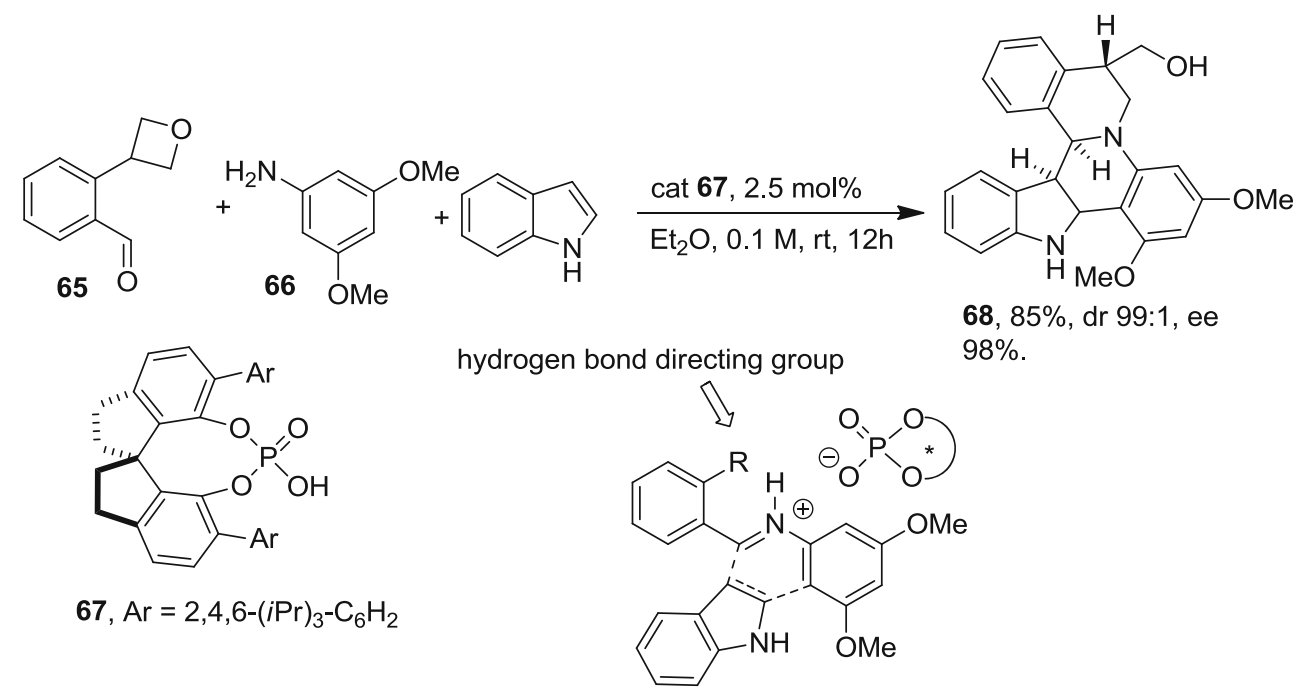

molecules were reported. The pyrrolo-isoquinoline moiety, that is present in the alkaloid families of erythrines [84] and lamellarins [85], is one of the structures that can be accessed through a multicomponent reaction. In 2012 Jørgensen reported [86] a three-component organocatalytic asymmetric reaction of imines, $\alpha$-bromoesters or $\alpha$-bromoketones with $\alpha, \beta$-unsaturated aldehydes to give optically active pyrrolo-isoquinolines 64, with excellent enantioselectivity for a large number of substituents showing broad scope for this reaction (Scheme 21). Computational studies shed light on the reaction pathway that proceeded in a stepwise manner. 


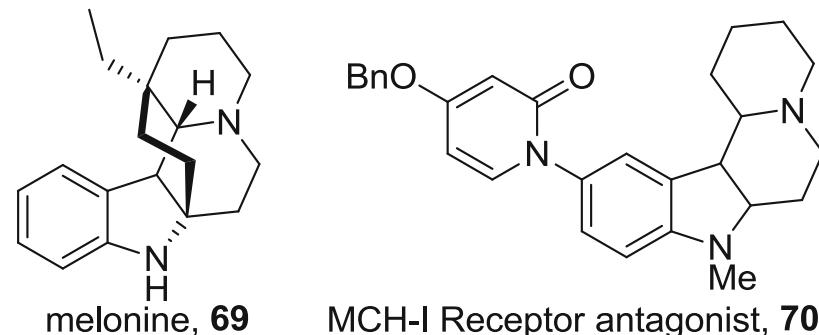

Fig. 7 Biologically active products that can be accessed through an asymmetric three components aza-Diels-Alder reaction

Zhu and Sun published a catalytic asymmetric threecomponent aza-Diels-Alder reaction using indole as the dienophile (Scheme 22) [87]. The presence of a directing group on the aldehyde $\mathbf{6 5}$ as hydrogen bond acceptor is mandatory for the success of the reaction.

The chiral phosphoric acid catalyst is involved in multiple hydrogen bonds and the oxetane moiety is also involved in the hydrogen bond recognition. Remarkably the isoquinoline indole-alkaloid-type polycyclic 68 products of the multicomponent reaction possess a core structure that is recognizable in melonine 69 and an MCH-I receptor antagonist $\mathbf{7 0}$ (Fig. 7).

3-Indolylmethanol derivatives have found many uses in organocatalysis as precursors of stabilized vinyliminium or carbocation intermediates species [88] that can be generated in the presence of a Lewis or Brønsted acid (LA or $\mathrm{BH})$. Shi, Tu and co-workers have used isatin-derived 3-indolylmethanols $\mathbf{7 1}$ as dipolarophiles for a formal catalytic asymmetric $[3+3]$ cycloaddition with azomethine ylides [89]. The desired spiro[indoline-3,4'-pyridoindoles] 73, were obtained in moderate diastereoselection but in excellent enantiomeric excess (up to $93 \%$, yield $>99 \%$ ) (Scheme 23). Chiral phosphoric acids are promoting the reaction through the formation of a stabilized vinyliminium in tight contact with the phosphate anion. Among all the catalysts tested for the reaction the acid $\mathbf{7 2}$ bearing bulky 9-phenanthrenyl group at the $3,3^{\prime}$-positions of the BINOL backbone exhibited the higher catalytic activity, when the reaction was performed in dichloroethane.

In a similar fashion, Gong and Luo described a multicomponent reaction that occurred with $p$-nitrobenzaldehyde, diethyl 2-aminomalonate, and 3-indolyl(aryl)methanols [90]. A formal, highly diastereoselective, chiral catalystcontrolled aza-Diels-Alder reaction between a 6-methoxytryptamine-derived dihydro- $\beta$-carboline $\mathbf{7 4}$ and an enantioenriched substituted enone $\mathbf{7 5}$ was described by Jacobsen (Scheme 24) [91, 92]. The key tetracyclic intermediate 77 was used for the total synthesis of (+)-reserpine $\mathbf{7 8}$.

\section{Amido Alkylation via Chiral Brønsted Acids}

The intramolecular attack on $N$-acyliminium ion electrophiles by $\pi$ nucleophiles can be used as a privileged methodology for the stereoselective construction of isoquinoline ring systems, by a cascade sequence. Taking inspiration from gold-(I)-catalysed chemistry, Dixon group identified a strategy based on the use of phosphoric acids [93] for efficient $N$-acyliminium cyclization [94-97]. First the reaction was optimized by studying the condensation of a keto amide intermediate, and when the most selective chiral phosphoric acid was found, the enantioselective $\mathrm{N}$-acyliminium cyclization cascade was realized (Scheme 25).

Different 5 or 6 membered unsaturated ring lactones and tryptamine derivatives were treated in toluene at $110{ }^{\circ} \mathrm{C}$ in
Scheme 23 Multicomponent reaction with 3 -indolylmethanol

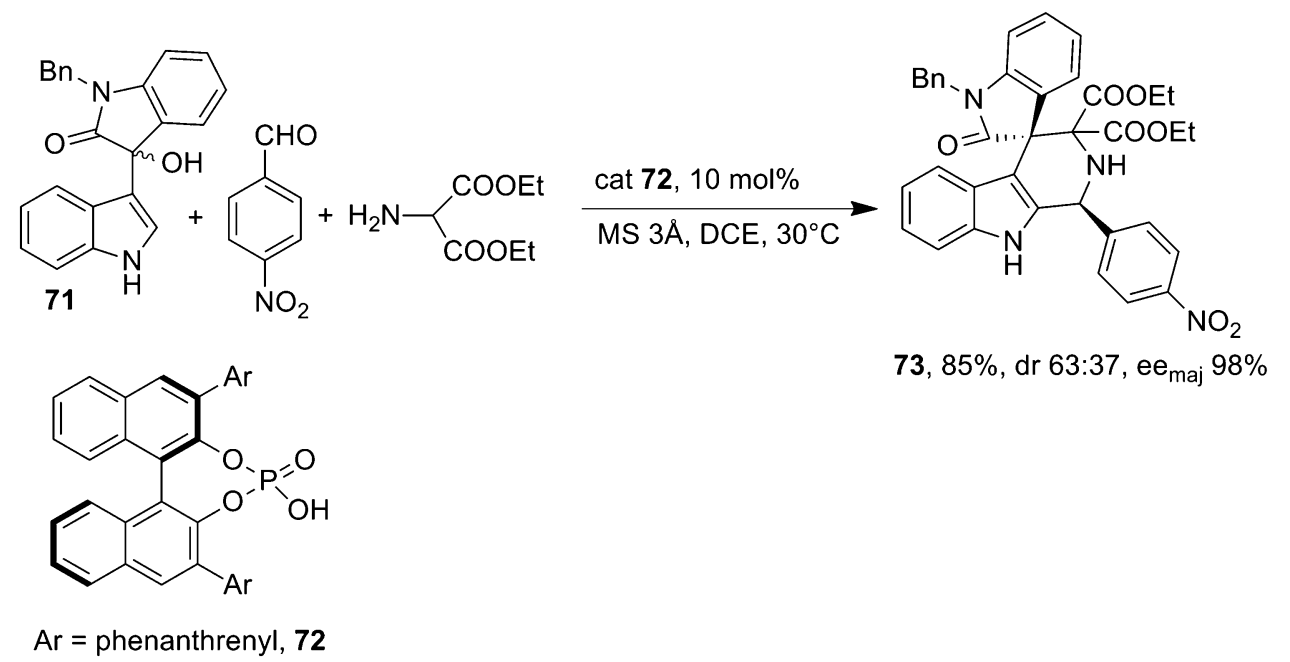




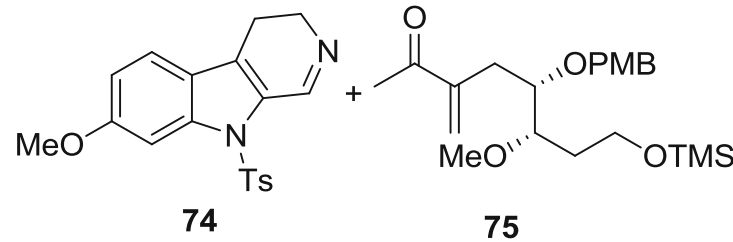

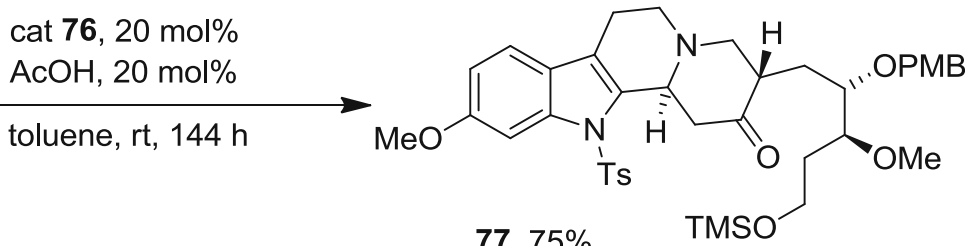<smiles>CC(C)(C)C[C@@H](NC(=S)N[C@H]1CCCC[C@H]1N)C(=O)N(c1ccccc1)C(C)(C)C</smiles><smiles>COC(=O)[C@H]1[C@@H]2C[C@@H]3c4[nH]c5ccccc5c4CCN3C[C@@H]2C[C@@H](OC(=O)c2cc(OC)c(OC)c(OC)c2)[C@@H]1OC</smiles>

(+)-reserpine, 78

Scheme 24 Stereoselective approach to reserpine thorough a diastereoselective, catalyzed controlled, formal aza-Diels-Alder reaction

Scheme 25 Cyclization cascade promoted by chiral phosphoric acid 46b

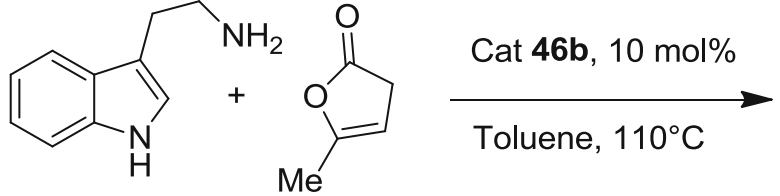

$34 a$<smiles>C[C@]12CCC(=O)N1CCc1c2[nH]c2ccccc12</smiles>

$79,99 \%$, ee $84 \%$
Scheme 26 Stereoselective amido alkylation promoted by TRIP<smiles>COc1ccc(CCN2C(=O)CCC2(C)O)cc1OC</smiles>

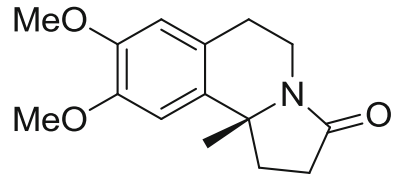

$81,31 \%$, ee $74 \%$ the presence of $10 \mathrm{~mol} \%$ of chiral catalyst $46 \mathbf{b}$. It is noteworthy that the high temperature is not depriving the stereoselective reaction. The yields obtained were in the range of $63-99 \%$ while the stereoselectivities were in between 72-99 \%. The high diastereo- and enantiocontrol observed in the reaction can be rationalized by a fast, reversible formation of the diastereomeric $N$-acyliminium salts followed by rate determining ring closure. As we have pointed out, the intramolecular Pictet-Spengler reaction promoted by chiral thioureas requires electron rich heteroaromatic systems, as indoles or pyrroles. However, Lete and co-workers reported the intramolecular Friedel-Craftstype $\alpha$-amidoalkylation using benzene derivatives as internal nucleophile to give functionalized tetrahydroisoquinoline derivatives $\mathbf{8 1}$ bearing a quaternary stereocenter (Scheme 26) [98].

The use of chiral phosphoric acids [99, 100] in this chemistry through the formation of a $\mathrm{N}$-acyliminium intermediate surrounded by chiral base anion gave, unfortunately, only moderate results. The reaction is sluggish and the yields are quite modest. The low nucleophilicity of the benzene aromatic substrates is probably responsible for the moderate success. Related to this reaction are the results reported by You [101], who has applied the formation of iminium promoted by a chiral phosphoric acid to a series of tetrahydro- $\beta$-carbolines $\mathbf{8 2}$. The derivatives $\mathbf{8 4}$ were obtained in 68-94\% yield and up to $90 \%$ ee (Scheme 27).

The reaction uses Hantzsch ester $\mathbf{8 3}$ as reductant. Its ability to behave as hydride donor was established in organocatalysis in various reactions [102], and it is strictly correlated to the nucleophilicity of hydride donors [103]. As it is well reported by Mayr the nucleophilicity of the hydrides are well suited for reacting with the iminium ions generated by Brønsted acids. In conjunction with this chemistry Enders reported a three-component reductive amination using another hydride donor, the substituted benzothiazoline $\mathbf{8 7}$ derivative, to obtain 1,3-disubstituted tetrahydroisoquinolines $\mathbf{8 8}$ in high yields and stereoselectivities (Scheme 28) [104]. 


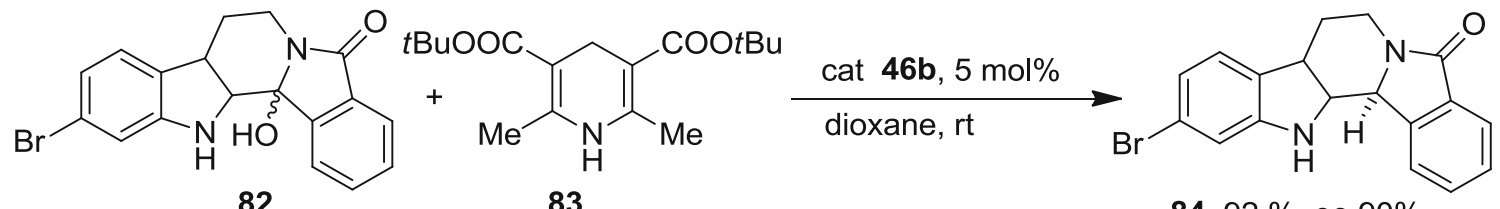

Scheme 27 Chiral phospsphoric acid catalyzed transfer hydrogenation of hydrolactams

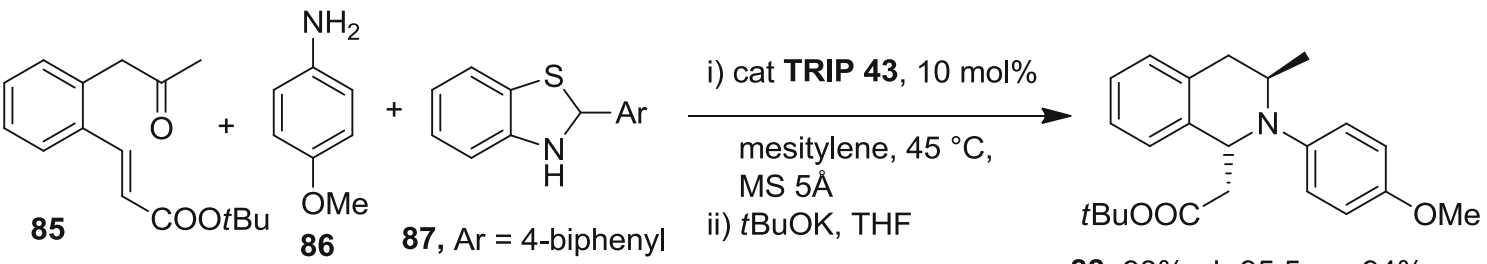

$88,93 \%$, dr $95: 5$, ee $94 \%$

Scheme 28 Reductive amination aza-Michael reaction

Scheme 29 Alkylation of a Reissert compounds to produce 1 -substituted isoquinolines<smiles>CCOC(=O)N1C=Cc2ccccc2[C@H]1C#N</smiles>

89, $\mathrm{Ar}=4-\mathrm{Br}-\mathrm{C}_{6} \mathrm{H}_{4}$<smiles>C=CC1CC2CCN1C([C@H](O)c1ccnc3ccc(OC)cc13)C2</smiles>

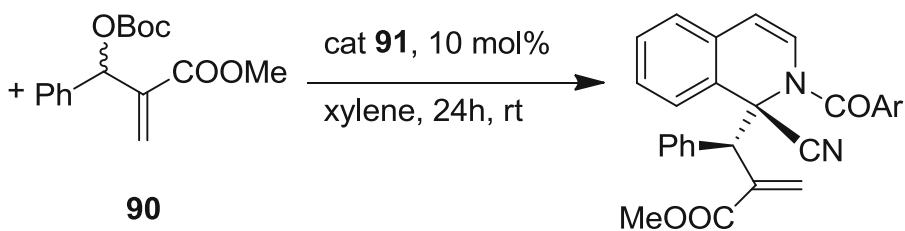

$92,98 \%$, dr $21: 1$, ee $87 \%$

\section{Reissert Adduct in Stereoselective Organocatalysis}

Reissert adducts, that can be simply obtained by catalytic addition of cyanide anion to isoquinoline, can be the precursors of a wide range of functionalities. They can be easily alkylated by electrophiles and we will illustrate the use of phase transfer catalysis (PTC) in the enantioselective alkylation of Reissert compounds, derived from various isoquinolines by the use of acyl chlorides or chloroformates as activating agents. A practical and stereoselective asymmetric allylic alkylation of 1,2-dihydro-Reissert compounds 89 was described by Zhang [105] disclosing a novel protocol to access highly functionalized 1,2-dihydroisoquinolines 92 bearing adjacent quaternary and tertiary stereocenters (Scheme 29).

The substrate for the allylic alkylation $\mathbf{8 9}$ is a useful and studied precursor in organocatalysis, due to the studies made by Chen and coworkers [106] and other groups [107]. The Lewis base-catalysed asymmetric allylic alkylation reactions in which Reissert adducts are used as substrates is often promoted by Cinchona alkaloid derivatives. The tertiary amino group of the quinidine alkaloid activates the substrates 89, that further reacts with suitable electrophiles through a push-pull mechanism in a chiral environment. The reaction proceeded smoothly and provided the desired product in good yield with excellent diastereoselectivity and high enantioselectivity ( $85 \%$ ee) in the presence of $10 \mathrm{~mol} \%$ quinidine $\mathbf{9 1}$, while the opposite enantiomer can be obtained by using $10 \mathrm{~mol} \%$ quinine. The absolute configuration was firmly established by X-ray analysis of a product derivative. Although the presence of various functional groups, the authors have not investigated the uses of these adducts in the synthesis of natural alkaloids.

\section{Phase Transfer Catalysis with Iminium in the Approach to Isoquinoline Derivatives}

Maruoka has recognized the practical and effective PTC [108] when applied to the synthesis of 1,1-disubstituted tetrahydroisoquinolines. A highly efficient catalytic asymmetric synthesis of 1,1-disubstituted tetrahydroisoquinolines 
Scheme 30 Asymmetric alkylation of 1-cyanotetrahydroisoquinolines promoted by PTC

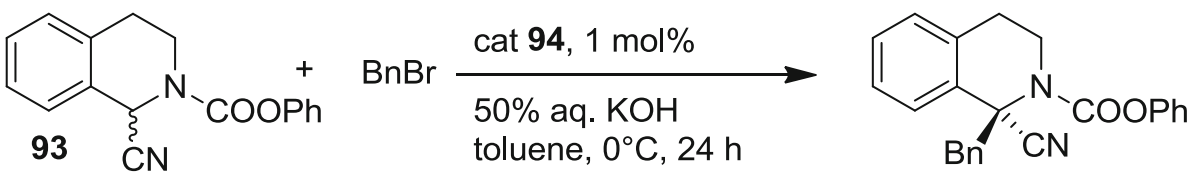

$95,73 \%$, ee $93 \%$

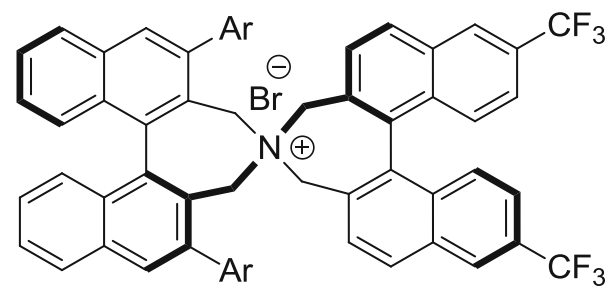

94, $\mathrm{Ar}=3,5-\left(\mathrm{CF}_{3}\right)_{2}-\mathrm{C}_{6} \mathrm{H}_{3}$

Scheme 31 Enantioselective PTC fluoroamination in the synthesis of isoquinolines<smiles></smiles>

97, 2,4,6-(Cy) $)_{3}-\mathrm{C}_{6} \mathrm{H}_{2}$<smiles>CC(C)(C)c1ccc(C(=O)N2C[C@]3(F)CCc4ccccc4C3=C[C@H]2c2ccccc2)cc1</smiles>

$98,91 \%$, dr $20: 1$, ee $96 \%$ was reported by Maruoka starting from the Reissert compounds via asymmetric alkylation or Michael addition [109]. The reaction is promoted by the use of $N$-spiro-type chiral phase-transfer catalyst 94 possessing the 3,5-bis(trifluoromethyl)phenyl groups and trifluoromethyl groups onto $3,3^{\prime}$-positions of one and the $6,6^{\prime}$-positions of one of the binaphthyl units (Scheme 30).

Benzylic bromides with different steric and electronic properties can be employed obtaining the corresponding products 95 in high yield and ees (84-94\% ee).

A new concept for the chiral-anion phase-transfer catalysis was reported by Toste [110] in the synthesis of octahydroisoquinoline derivatives [111]. Respect to the previous described methodologies, in which the counter ion is surrounding the nucleophiles in a homogeneous solution, the strategy developed by Toste is able to bring an insoluble cationic reagent into the solution. An electrophilic fluorinating reagent (Selecfluor), insoluble in nonpolar media, is brought into an apolar solution by the anion exchange with a lipophilic, bulky chiral phosphate anion. With this strategy an enantioselective 1,4- aminofluorocyclization of 1,3-dienes 96 that gave in good yield and stereoselectivity benz[f]isoquinolines 98 through an 6-endo-trig cyclization was described (Scheme 31).

\section{Conclusion and Perspective}

In this brief and limited overview we have presented a few of the activation modes that can be used in designing successful organocatalytic reactions to access isoquinoline derivatives in a stereocontrolled manner. Many other activations modes, such as dienamine [112], trienamine [113] and tetraenamine [114] catalysis, SOMO reactions [115] and $\beta$-activation of simple aldehyde substrates [116] will be certainly explored in near future in the synthesis of useful intermediates. Stereoselective addition of ketones [117] and $\gamma$-alkylation with unsaturated aldehydes [118] to isoquinolinium are possible and will be presented. All these reactions, that occurred in simple and scalable conditions, will certainly help medicinal chemists to prepare analogous 
of alkaloids, leading to the discovery of new effective and powerful drugs.

\section{References}

1. Shamma M (1972) The Isoquinoline Alkaloids, Vol 25. Academic Press, London or Verlag Chemie, Weinheim

2. Kittakoop P, Mahidol C, Ruchirawat S (2014) Curr Top Med Chem 14:239

3. Hesse M (2002) Alkaloids: nature's curse or blessing? Wiley$\mathrm{VCH}$, Weinheim

4. Rozwadowska MD (1994) Heterocycles 39:903

5. Czarnocki Z, Siwicka A, Szawkalo J (2005) Curr Org Chem 2:301

6. Ahamed M, Todd MH (2010) Eur J Org Chem 31:5935-5942

7. Bentley KW(2006) Nat Prod Rep 23: 444 and previous reviews in this series

8. Reissert A (1905) Ber Dtsch Chem Ges 38:1603

9. Takamura M, Funabashi K, Kanai M, Shibasaki M (2001) J Am Chem Soc 123:6801

10. Lin W, Cao T, Fan W, Han Y, Kuang J, Luo H, Miao B, Tang X, Yu Q, Yuan W, Zhang J, Zhu C, Ma S (2014) Angew Chem Int Ed 53:277 and references therein

11. Ye ZS, Guo RN, Cai XF, Chen MW, Shi L, Zhou YG (2013) Angew Chem Int Ed 52:3685

12. Wu Z, Perez M, Scalone M, Ayad T, Ratovelomanana-Vidal V (2013) Angew Chem Int Ed 52:4925

13. Wilson YM, Dürrenberger M, Nogueira ES, Ward TR (2014) J Am Chem Soc 136:8928

14. List B, Lerner RA, Barbas III CF (2000) J Am Chem Soc 122:2395

15. Ahrendt KA, Borths JC, MacMillan DWC (2000) J Am Chem Soc 122:4243

16. MacMillan DWC (2008) Nature 455:304

17. Burés J, Dingwall P, Armstrong A, Blackmond DG (2014) Angew Chem Int Ed 53:8700

18. Mayr H, Lakhdar S, Maji B, Ofial AR (2012) Beilstein J Org Chem 8:1458

19. Marquès-Lòpez E, Herrera RP, Christmann M (2010) Nat Prod Rep 27:1138

20. Ricci A (2014) ISRN Org Chem. doi:10.1155/2014/531695

21. Mukherjee S, Yang JW, Hoffmann S, List B (2007) Chem Rev 107:5471

22. Erkkilä A, Majander I, Pihko PM (2007) Chem Rev 107:5416

23. Petruzziello D, Stenta M, Mazzanti A, Cozzi PG (2013) Chem Eur J 19:7696

24. Moran A, Hamilton A, Bo C, Melchiorre P (2013) J Am Chem Soc 135:9091

25. Seebach D, Grosĕlj U, Badine DM, Schweizer WB, Beck AK (2008) Helv Chim Acta 91:1999

26. Palomo C, Mielgo A (2006) Angew Chem Int Ed 45:7876

27. Hoang L, Bahmanyar S, Houk KN, List B (2003) J Am Chem Soc 125:16

28. Mayr H, Bug T, Gotta MF, Hering N, Irrgang B, Janker B, Kempf B, Loos R, Ofial AR, Remennikov G, Schimmel H (2001) J Am Chem Soc 123:9500

29. Mayr H, Ofial AR (2008) J Phys Org Chem 21:584

30. Mayr H, Kempf B, Ofial AR (2003) Acc Chem Res 36:66

31. Gualandi A, Cozzi PG (2013) Synlett 24:281

32. Boess E, Schmitz C, Klussmann M (2012) J Am Chem Soc 134:5317

33. Boess E, Sureshkumar D, Sud A, Wirtz C, Farès C, Klussmann M (2011) J Am Chem Soc 133:8106
34. Lakhdar S, Tokuyasu T, Mayr H (2008) Angew Chem Int Ed 47:8723

35. Knowles RR, Jacobsen EN (2010) PNAS 107:20668

36. Yoon TP, Jacobsen EN (2003) Science 299:1691

37. Enders D, Niemeier O, Henseler A (2007) Chem Rev 107:5606

38. Morrill LC, Smith AD (2014) Chem Soc Rev 43:6214

39. Grossmann A, Enders D (2012) Angew Chem Int Ed 51:314

40. Maji B, Mayr H (2013) Angew Chem Int Ed 52:11163

41. Maji B, Mayr H (2012) Angew Chem Int Ed 51:10408

42. Phillipson JD, Roberts MF, Zenk MH (eds) (1985) The chemistry and biology of isoquinoline alkaloids. Springer Verlag, Berlin

43. Chrzanowska M, Rozwadowska MD (2004) Chem Rev 104:3341

44. Frisch K, Landa A, Saaby S, Jørgensen KA (2005) Angew Chem Int Ed 44:6058

45. Akiba K, Nakatani M, Wada M, Yamamoto Y (1985) J Org Chem 50:63

46. Mengozzi L, Gualandi A, Cozzi PG (2014) Chem Sci 5:3915

47. Calonghi N, Naso F, Mengozzi L, Gualandi A, Cozzi PG, unpublished results

48. Mattioli EJ, Mengozzi L, Gualandi A, Cozzi PG, unpublished results

49. Taylor MS, Tokunaga N, Jacobsen EN (2005) Angew Chem Int Ed 44:6700

50. Schafer AG, Wieting JM, Fisher TJ, Mattson AE (2013) Angew Chem Int Ed 52:11321

51. De Kanta C, Mittal N, Seidel D (2011) J Am Chem Soc 133:16802

52. Höfle G, Steglich W, Vorbrüggen H (1978) Angew Chem Int Ed Engl 17:569

53. De Kante C, Seidel D (2011) J Am Chem Soc 133:14538

54. Girard SA, Knauber T, Li CJ (2014) Angew Chem Int Ed 53:74

55. Cherevatskaya M, Neumann M, Füldner S, Harlander C, Kümmel S, Dankesreiter S, Pfitzner A, Zeitler K, König B (2012) Angew Chem Int Ed 51:4062

56. Dhineshkumar J, Lamani M, Alagiri K, Prabhu KR (2013) Org Lett 15:1092

57. Xue Q, Xie J, Jin H, Cheng Y, Zhu C (2013) Org Biomol Chem $11: 1606$

58. Zhang J, Tiwari B, Xing C, Chen X, Chi YR (2012) Angew Chem Int Ed 51:3649

59. Zhang G, Ma Y, Wang S, Kong W, Wang R (2013) Chem Sci $4: 2645$

60. Shi Z, Zhang C, Tang C, Jiao N (2012) Chem Soc Rev 41:3381

61. Zhang G, Ma Y, Wang S, Zhang Y, Wang R (2012) J Am Chem Soc 134:12334

62. Neel AJ, Hehn JP, Tripet PF, Toste FD (2013) J Am Chem Soc 135:14044

63. Hein JE, Fokin VV (2010) Chem Soc Rev 39:1302

64. Nicewicz D, MacMillan DWC (2008) Science 322:77

65. Prier CK, Rankic DA, MacMillan DWC (2013) Chem Rev 113:5322

66. Di Rocco DA, Rovis T (2012) J Am Chem Soc 134:8094

67. Ryan SJ, Candish L, Lupton DW (2013) Chem Soc Rev 42:4906

68. Vora HU, Rovis T (2011) Aldrichimica Acta 44:3

69. For the chemistry related of carbene intermediate oxidation, see: Mo J, Shen L, Chi RY (2013) Angew Chem Int Ed 52:8588

70. Bergonzini G, Schindler CS, Wallentin CJ, Jacobsen EN, Stephenson CRJ (2014) Chem Sci 5:112

71. Stöckigt J, Antonchick AP, Wu F, Waldmann H (2011) Angew Chem Int Ed 50:8538

72. Taylor MS, Jacobsen EN (2004) J Am Chem Soc 126:10558

73. Raheem IT, Thiara PS, Peterson EA, Jacobsen EN (2007) J Am Chem Soc 129:13404

74. Lin S, Jacobsen EN (2012) Nature Chem 4:817 
75. Klausen RS, Jacobsen EN (2009) Org Lett 11:887

76. Seayad J, Seayad AM, List B (2006) J Am Chem Soc 128:1086

77. Wanner MJ, Van der Haas RNS, De Cuba KR, Van Maarseveen JH, Hiemstra H (2007) Angew Chem Int Ed 46:7485

78. Sewgobind NV, Wanner MJ, Ingemann S, De Gelder R, Van Maarseveen JH, Hiemstra H (2008) J Org Chem 73:6405

79. Herlé B, Wanner MJ, Van Maarseveen JH, Hiemstra H (2011) J Org Chem 76:8907

80. Kerschgens IP, Claveau E, Wanner MJ, Ingemann S, Van Maarseveen JH, Hiemstra H (2012) Chem Comm 48:12243

81. Lee Y, Klausen RS, Jacobsen EN (2011) Org Lett 13:5564

82. Mons E, Wanner MJ, Ingemann S, Van Maarseveen JH, Hiemstra H (2014) J Org Chem 79:7380

83. Ruijter E, Scheffelaar R, Orru RVA (2011) Angew Chem Int Ed 50:6234

84. Ozawa M, Kawamata S, Etoh T, Hayashi M, Komiyama K, Kishida A, Kuroda C, Ohsaki A (2010) Chem Pharm Bull 58:1119

85. Pla D, Albericio F, Àlvarez M (2011) Med Chem Commun 2:689

86. Fraile A, Scarpino Schietroma DM, Albrecht A, Davis RL, Jørgensen KA (2012) Chem Eur J 18:2773

87. Chen Z, Wang B, Wang Z, Zhu G, Sun J (2013) Ang Chem Int Ed 52:2027

88. Cozzi PG, Benfatti F, Zoli L (2009) Angew Chem Int Ed 48:1313

89. Shi F, Zhu RY, Dai W, Wang CS, Tu SJ (2014) Chem Eur J 20:2597

90. Huang J, Luo S, Gong L (2013) Acta Chim Sin 71:879

91. Lalonde MP, McGowan MA, Rajapaksa NS, Jacobsen EN (2013) J Am Chem Soc 135:1891

92. Rajapaksa NS, McGowan MA, Rienzo M, Jacobsen EN (2013) Org Lett 15:706

93. Terada M (2011) Curr Org Chem 15:2227

94. Muratore ME, Holloway CA, Pilling AW, Storer RI, Trevitt G, Dixon DJ (2009) J Am Chem Soc 131:10796

95. Muratore ME, Shi L, Pilling AW, Storer RI, Dixon DJ (2012) Chem Comm 48:6351
96. Holloway CA, Muratore ME, Storer RI, Dixon DJ (2010) Org Lett 12:4720

97. Aillaud I, Barber DM, Thompson AL, Dixon DJ (2013) Org Lett $15: 2946$

98. Gòmez-SanJuan A, Sotomayor N, Lete E (2012) Tetrahedron Lett 53:2157

99. Terada M (2010) Synthesis 12:1929

100. Akiyama T (2007) Chem Rev 107:5744

101. Yin Q, Wang SG, You SL (2013) Org Lett 15:2688

102. Zheng C, You SL (2012) Chem Soc Rev 41:2498

103. Horn M, Schappele LH, Lang-Wittkowski G, Mayr H, Ofial AR (2013) Chem Eur J 19:249

104. Enders D, Liebich JX, Raabe G (2010) Chem Eur J 16:9763

105. Qin TY, Liao WW, Zhang JY, Zhang SXA (2013) Org Biomol Chem 11:984

106. Liu TY, Xie M, Chen YC (2012) Chem Soc Rev 41:4101

107. Rios R (2012) Catal Sci Technol 2:267

108. Shirakawa S, Maruoka K (2013) Ang Chem Int Ed 52:4312

109. Shirakawa S, Liu K, Ito H, Le TN, Maruoka K (2011) Adv Synth Catal 353:2614

110. Rauniyar V, Lackner AD, Hamilton GL, Toste FD (2011) Science 334:1681

111. Shunatona HP, Früh N, Wang YM, Rauniyar V, Toste FD (2013) Angew Chem Int Ed 52:7724

112. Albrecht L, Dickmeiss G, Acosta FC, Rodríguez-Escrich C, Davis RL, Jørgensen KA (2012) J Am Chem Soc 134:2543

113. Kumar I, Ramaraju P, Mir NA (2013) Org Biomol Chem 11:709

114. Stiller J, Poulsen PH, Cruz DC, Dourado J, Davis RL, Jørgensen KA (2014) Chem Sci 5:2052

115. Devery JJ III, Conrad JC, MacMillan DWC, Flowers RA II (2010) Angew Chem Int Ed 49:6106

116. Pirnot MT, Rankic DA, Martin DBC, MacMillan DWC (2013) Science 339:1593

117. Benelli C, Gualandi A, Mengozzi L, Cozzi PG, manuscript in preparation

118. Gualandi A, Mengozzi L, Cozzi PG, manuscript in preparation 